This document is confidential and is proprietary to the American Chemical Society and its authors. Do not copy or disclose without written permission. If you have received this item in error, notify the sender and delete all copies.

\title{
Using Molecular Initiating Events to Generate 2D Structure Activity Relationships for Toxicity Screening
}

\begin{tabular}{|r|l|}
\hline Journal: & Chemical Research in Toxicology \\
\hline Manuscript ID & tx-2016-00101y.R2 \\
\hline Manuscript Type: & Article \\
\hline Date Submitted by the Author: & $\mathrm{n} / \mathrm{a}$ \\
\hline & $\begin{array}{l}\text { Allen, Timothy; University of Cambridge, Department of Chemistry } \\
\text { Liggi, Sonia; University of Cambridge, Department of Chemistry } \\
\text { Goodman, Jonathan; University of Cambridge, Department of Chemistry } \\
\text { Gussell, Paul; Unilever Safety and Environmental Assurance Centre }\end{array}$ \\
\hline
\end{tabular}

\section{SCHOLARONE \\ Manuscripts}




\section{Using Molecular Initiating Events to Generate 2D}

\section{Structure Activity Relationships for Toxicity}

\section{Screening}

Timothy E. H. Allen, $\uparrow$ Sonia Liggi,, Jonathan M. Goodman, ${ }^{*}+$ Steve Gutsell,,+ and Paul J.

Russell:t

$\dagger$ Centre for Molecular Informatics, Department of Chemistry, University of Cambridge, Lensfield Road, Cambridge, CB2 1EW, United Kingdom

¥Unilever Safety and Environmental Assurance Centre, Colworth Science Park, Sharnbrook, Bedfordshire, MK44 1LQ, United Kingdom

KEYWORDS: Molecular Initiating Event (MIE), Structure Activity Relationship (SAR), Adverse Outcome Pathway (AOP), Human Toxicology, Risk Assessment. 
Table of Contents Graphic

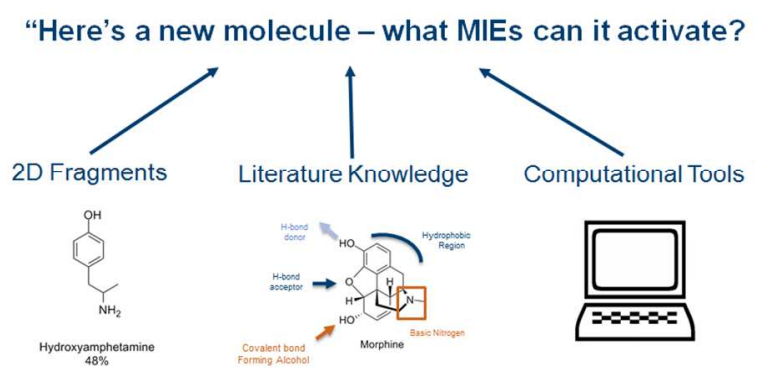

16

17

18

19

20

21

22

23

24

25

26

27

28

29

30

31

32

33

34

35

36

37

38

39

40

41

42

43

44

45

46

47

48

49

50

51

52

53

54

55

56

57

58

59

60

ACS Paragon Plus Environment 


\begin{abstract}
Molecular initiating events (MIEs) can be boiled down to chemical interactions. Chemicals that interact must have intrinsic properties that allow them this behavior, be these stereochemical, electronic or otherwise. In an attempt to discover some of these chemical characteristics we have constructed structural alert-style structure activity relationships (SARs) to computationally predict MIEs. This work utilizes chemical informatics approaches, searching the ChEMBL database for molecules that bind to a number of pharmacologically important human toxicology targets, including G-protein coupled receptors (GPCRs), enzymes, ion channels, nuclear receptors, and transporters. By screening these compounds to find common 2D fragments, and combining this approach with a good understanding of the literature, bespoke 2D structural alerts have been written. These SARs form the beginning of a tool for screening novel chemicals to establish the kind of interactions they may be able to make in humans. These SARs have been run through an internal validation to test their quality and the results of this are also discussed. MIEs have proven to be difficult to find and characterize but we believe we have taken a key first step with this work.
\end{abstract}

\title{
INTRODUCTION
}

The molecular initiating event (MIE) has been defined as a key chemical event in toxicity leading to adverse outcomes through adverse outcome pathways (AOPs). ${ }^{1,2}$ With its basis strongly founded in chemistry, the MIE makes a good starting point for the development of in silico tools, such as structure activity relationships (SARs). In order for a chemical (or metabolite/breakdown product) to cause an effect via an MIE it must conform to specific 
chemical characteristics: those which allow it to bind to a receptor, inhibit an enzyme, or modify a protein. An MIE is essentially a chemical interaction. The links between these chemical characteristics and the MIE will undoubtedly be stronger than links to a toxicological endpoint, which is much further down the pathway.

The AOP framework for risk assessment brings together chemical and biological understanding in an attempt to develop predictive methods for human and environmental toxicology. ${ }^{3,4}$ AOPs span multiple levels of biological organization, and as such a large amount of knowledge is required to make an AOP risk assessment. This will consist of knowledge of the exposure of an organism to a chemical, followed by an understanding of how that chemical is absorbed, distributed, metabolized and excreted and hence how much of the chemical gets to the active site. Once the chemical reaches the active site how, and to what extent, does it bind to, or interact with, a target? How does this interaction lead to a disturbance of the biosystem within this organism and, finally, how does this disturbance leads to effects at a measurable, level of biological organization? This is indeed a large undertaking. However, the AOP provides a framework that, once these pieces are in place, can provide a genuine alternative to in vivo testing. ${ }^{5-7}$

MIEs are already being used as gateways to the development of predictive tools and mechanistic understanding. The MIE has been used in quantitative structure activity relationship (QSAR) development $^{8}$ and category formation and read across ${ }^{9}$ within in silico tools. Molecular modelling is also finding a use for the MIE, in research leading to an increase in mechanistic understanding of biological-chemical interactions. ${ }^{10}$ Once the potential for a compound to activate an MIE has been established, this can be linked to in vitro studies of downstream biomarkers associated with known AOPs, allowing risk assessment to be carried out. 
The development, evaluation and current trends in SAR and QSAR research have been well reviewed. ${ }^{11,12}$ Despite advances in these powerful in silico techniques they are still treated with some suspicion in the toxicology community. Their role in toxicology risk assessment is generally confined to chemical screening. ${ }^{2}$ Anchoring SARs and QSARs at the MIE removes large amounts of biological complexity from the models, providing stronger links between chemical characteristics and the prediction of adverse outcomes. The construction of clear models with sound theoretical backing is of great importance, and these will illustrate the value of the technique.

One such type of SAR in toxicity prediction relies on the use of structural fragments from within molecules to distinguish active compounds from inactive ones. One such approach has been used in the development of SAR "rules" for skin sensitization. ${ }^{13}$ Similar approaches are used within computational tools, such as Derek Nexus, a knowledge-based expert system for qualitative toxicity prediction based on chemical structure. ${ }^{14}$ The OECD QSAR toolbox (http://www.oecd.org/chemicalsafety/risk-assessment/theoecdqsartoolbox.htm) provides a further example of the use of chemical characteristics being linked to potential mechanism or mode of action. ${ }^{15}$ The use of structural alerts can be associated with MIEs in predictive toxicology and tools to make these predictions are already under development. ${ }^{16,17}$

The aim of this work is to build a structural alert-style SAR approach to predict MIEs in silico. This study has been conducted with a number of pharmacologically important human targets for systemic toxicity drawn from a paper by Bowes in $2012^{18}$, and several targets of interest from our previous work. ${ }^{1}$ In particular the Bowes receptors are highlighted as pharmacologically important off-target interactions, often leading to the failure of new drug candidates in clinical trials. ${ }^{18}$ These receptors are also of importance in the development of ingredients for consumer 
goods products as they could lead to damaging systemic toxicity outcomes. As important drug safety targets these receptors are also likely to have a good amount of biological in vitro data available for analysis and the construction of models, providing a further advantage. In addition to this these targets cover a wide variety of different biomolecules, and a good representation of biological space. As such these receptors provide a good starting point for the development of any in silico technique. These targets include G-protein coupled receptors (GPCRs), enzymes, ion channels, nuclear receptors and transporters (Table 1).

These biological targets require MIEs to be described in a different way to the well-characterized skin sensitization alerts based on chemical reactivity, ${ }^{19}$ because binders are likely to sit in a sterically restricted receptor binding pockets or enzyme active sites and interact with the biomolecule through hydrogen bonds, or charge-charge and hydrophobic interactions. Fortunately structural and pharmacophore-style 2D fragments coded in SMILES and SMARTS can still describe these alerts well.

2D fragment based approaches to SARs have several advantages. They are computationally simple, allowing the rapid assessment of a large number of chemicals without the use of a large amount of computational resources. 2D SARs are also mechanistically transparent, and can be easily interpretable as to what it is about a molecule that causes it to activate an MIE. Despite this they do have their limitations. For example, this strategy only locates common substructures in the training data when a relatively large common molecular scaffold is available. Some biological targets are promiscuous and only slight changes in the chemistry of binders results in a large change in biological activity, which is sometimes difficult to describe with a chemical fragment. These fragments also do not analyze the chemical characteristics of whole molecules, and so important pieces of information can be missed if they are just outside of the located 
fragment. Finally using 2D substructures to model 3D environments is considered an incomplete way to predict biological activity. The shape and size of a molecule may play a bigger role in its ability to fit into, and bind to, a biological target than its chemical features, particularly if the target is a well-defined enzyme active site. This can only be assessed in 3D.

One target may have more than one MIE. From a chemical perspective it is also true that one binding pocket may allow chemicals to bind to it through different interactions, and these may lead to a diversity of alerts. The alerts in this paper are for a specific "mode of binding" (MOB) and this term will be used in this study to avoid confusion. Without additional biological understanding, it is sometimes not clear if two alerts apply to the same MIE, or to different ones.

\section{MATERIALS AND METHODS}

Data Set. ChEMBL (https://www.ebi.ac.uk/chembl/, version 19, extracted November 2014) was used, containing more than a million annotated compounds, comprising more than twelve million bioactivities covering more than 10000 targets, all abstracted from the primary scientific literature. ${ }^{20}$ Compounds with a confidence score of 8 or 9 and with reported activities $\left(\mathrm{K}_{\mathrm{i}} / \mathrm{K}_{\mathrm{d}} / \mathrm{IC50} / \mathrm{EC} 50\right)$ better than, or equal to, $10 \mu \mathrm{M}$ against human protein targets were treated as positives and used for model generation. These cutoffs were chosen to provide chemicals with a pharmacologically-relevant activity at a specific, well-defined, human target. A cut-off of $10 \mu \mathrm{M}$ will ensure that the compounds have a good degree of biological activity and represents a tradeoff between activity and dataset size. A confidence score of 8 represents the assignment of homologous single proteins, and 9 direct single protein interactions. ${ }^{21}$ These compounds are binders irrespective of agonistic and antagonistic activity. Non-binders were omitted from the generation of the models because of the small fraction of compounds found in ChEMBL with 
reported activities below $10 \mu \mathrm{M}$. Only receptors with at least twenty active compounds were used to ensure enough information is available to construct appropriate in silico models. The data set for each target was split randomly into $75 \%$ training set and a $25 \%$ test set using a function in Pipeline Pilot, ${ }^{22}$ so internal validation could be provided. The data were uniquified to ensure no duplicate data corrupted results. This was performed on the molecular structure of each chemical based on their atomic connectivity, resulting in different tautomers, enantiomers and salts being treated as different data points. The training sets were then combined and uniquified to make an amalgamated training set, and the test sets were combined in an analogous fashion to make an amalgamated test set. These give a representation of ChEMBL chemical space. The amalgamated training set was used to provide fragments present across the whole set. It was not used in the development of models. The amalgamated test set was used in the internal validation. These compounds had unknown activity across each receptor but were used as anticipated negatives to give an idea of chemical space. This is done to overcome bias in the ChEMBL set towards positives, and allow model quality to be better assessed than through the use of sensitivity alone. In total 51179 activities across 30349 unique compounds and 45 human targets (Table 1) were extracted for model construction.

Model Construction. The compound's canonical SMILES were used to generate 2D fragmentbased structural alerts using custom scripting in Pipeline Pilot. ${ }^{22}$ Molecular fragments were identified based on matching atom types and charges between molecules. Partial aliphatic rings were allowed within fragments. The fragment size and frequency within the training set were altered to sample a diversity of potentially active fragments. The outputs were viewed and curated manually to identify key fragments which are associated with positive activity, rather than just being common among medicinal chemicals. Text based literature searches were 
conducted using SciFinder to find information on targets that could aid in the construction of models. In some cases, crystal structures were found. In others, well-known molecules with precisely understood binding behavior were found and the structures of these compared to the found fragments. Based on the elucidated fragments, and understanding gained through the literature searches, structural alerts were coded as SMILES strings or SMARTS and models were constructed using a substructure filter.

Internal Validation. Test sets were used to calculate sensitivity (SE) for each structural alert.

$$
S E=\frac{T P}{T P+F N}
$$

In order to provide a negative test set for each human receptor target the test set for the target of interest was subtracted from the amalgamated test set. As such every negative test set is not the same. This is to give an idea of chemical space, but the chemicals are untested against the target of interest and are treated as negatives only for the purpose of this analysis. This is done to provide analysis and get a confidence score for models. As such these results must be treated carefully, but should provide more guidance greater than sensitivity-only calculations. Specificity (SP) is calculated from these results.

$$
S P=\frac{T N}{T N+F P}
$$

Overall quality $(\mathrm{Q})$ is calculated based on the total number of correct predictions.

$$
Q=\frac{T P+T N}{T P+T N+F P+F N}
$$


To overcome the issue of having a larger negative test set than positive the Matthews correlation coefficient (MCC) was used; ${ }^{23}$

$$
M C C=\frac{T P \times T N-F P \times F N}{\sqrt{(T P+F P)(T P+F N)(T N+F P)(T N+F N)}}
$$

\section{RESULTS AND DISCUSSION}

Amalgamated Set

In the search for common 2D fragments in the ChEMBL dataset it is inevitable that some fragments will be found that are simply common among medicinal chemicals within ChEMBL. In order to take this into account, and to prevent models being built using fragments that are simply common across the entire dataset of all receptors, a bespoke model building process is used. The fragments are subjected to human analysis, and appropriate fragments selected, rather than simply using a computer to select all fragments. In addition to this, a dataset was constructed containing all compounds across all test sets analyzed in this study. This training set was uniquified, and then run through the same protocols used to generate $2 \mathrm{D}$ fragments for each receptor. This generated a number of fragments that are simply common among medicinal chemicals of this type, and so should not be considered indicative of any particular receptorligand interaction, unless exceptionally high percentages of the training set include them. These are shown in Figure 1.

As may have been expected, some fragments, including benzene rings, aliphatic amines, and short carbon chains are commonly present.

Structural Alerts 
Across the 45 human targets analyzed in this work, 126 structural alerts have been developed, and these are shown in Table 2. These structural alerts include those found using maximal common substructure searches using Pipeline Pilot, those found in typical ligands for the target, those identified in previously accepted pharmacophores, those identified in existing crystal structures, and combinations of these. Each alert is labelled in Table 2 to indicate its origin and pharmacophores, crystal structures and typical binders found in the literature are referenced. The SMILES and SMARTS that were coded for these structural alerts are provided in supporting information. Table 2 also provides the fraction of positives identified by each alert in the training set.

Results for the internal validation of structural alerts are shown in Table 3 . A total of 126 alerts have been produced across 45 human targets. In large part this has been successful, with 77 models across 39 targets producing MCC values of greater than 0.2 (representing $60 \%$ correct predictions for a balanced data set), 28 models across 21 targets giving MCC values greater than 0.4 (70\% correct predictions for a balanced data set), and seven models across seven receptors scoring MCC values of greater than 0.6 (80\% correct predictions for a balanced data set) in internal validation. These results must be treated with a note of caution, however, as the remainder of the ChEMBL training set was used as a negative test set, meaning these compounds have not been confirmed as true negatives. Despite this, these results show that the structural alerts that have been developed do not tend to over-fire, and as such the results obtained by running a novel chemical through these structural alerts should be of benefit to a toxicologist wanting to be able to perform a pragmatic risk assessment when combined with other data, or identify targets of interest for further investigation. 
This study has produced an average of just under three structural alerts (2.93) per target. It is notable that a number of targets have only one structural alert covering a large proportion of their active compounds (Dihydrofolate reductase, GAR transformylase, tyrosine-protein kinase, the glutamate (NMDA) receptor, the HERG channel, and the voltage gated K channel subunit Kv7.1). This suggests that these biological targets are quite specific in the compounds that they accept and hence there is less structural variability in their binders. Only two targets have more than five fragments, the adrenergic 2 a receptor (6) and monoamine oxidase (7), indicating that these are more promiscuous receptors with more structurally varied binders.

Combined Models

2D structural alerts, such as those developed in this work, can be used in toxicity screening, as a hazard identification tool, or as a tool in risk assessment to support a decision on chemical safety. In each of these cases the structural alerts will be used in different ways. In hazard identification tools need to be calibrated to provide maximum safety; that is to minimize the number of false negatives at the expense of the number of false positives predicted. In risk assessment tools will be adjusted to provide maximum accuracy; to provide the best possible predictivity as measured by a metric such as MCC.

To provide results on the structural alerts developed in this work for hazard identification, the structural alerts for each target were combined into a model requiring a molecule to contain any of the structural alerts to be predicted a positive. These models were tested against the positive test set for each target to provide a sensitivity value in each case. These results are shown in Table 4. This provides perspective on the proportion of binders likely to be predicted by these models, in a hazard assessment exercise. 45 models were tested and their sensitivity values 
calculated. 29 models scored sensitivity values of $50 \%$ or more, 13 scored $75 \%$ or more and five scored $90 \%$ or more. These results provide a promising basis for the construction of a toxicity screening tool for hazard identification based on these structural alerts predicting MIEs. 2D structural alert methods such as this have an advantage in hazard assessment as they are computationally quick and inexpensive, and often hazard assessment requires the processing of large numbers of chemicals to screen out potentially toxic molecules at an early stage of compound development.

Risk assessment for individual chemicals is very different to hazard identification, and as such requires a different approach. Small numbers of chemicals are assessed on a case-by-case basis to ensure their safety. This requires expert input and pragmatic decision making by an expert scientist, and as such a batch test of these structural alerts is not an appropriate way to assess their value. 2D structural alerts such as these may find use in this field, and if they do it is important that the expert takes into account the results from our study to make an informed decision as to whether a chemical is likely to bind to a given target or not. The statistical results for sensitivity, specificity, overall quality and MCC values provided in Table 2 give guidance as to which of the alerts are most predictive and which are likely to over-fire. Alerts with a high sensitivity and MCC are very predictive and should be most useful in risk assessment. Alerts with a low specificity are hitting a number of compounds that are not considered binders in ChEMBL, and as such will produce a large number of false positives in risk assessment.

Further research will be required to expand our work to other key MIEs and improve it to the point where it can quantitatively predict the amount of a toxicant required at a target to exhibit a toxicological response. In addition to this a number of other tools will be required to accurately predict the amount of a toxicant that is able to reach the site of the MIE, and the biological 


\begin{abstract}
response that will result from the activation of the MIE, in order to represent a complete risk assessment.
\end{abstract}

\title{
Biological Relevance
}

The AOP Wiki represents the best current repository for AOP information, and as such a search was performed to identify AOPs which could result from the binding of a molecule to the targets examined in this work. ${ }^{24}$ The majority of the AOPs that may be associated with this work are currently under development (totaling 19 pathways) and the associated targets are listed below:

- Acetylcholinesterase

- Androgen Receptor

- $\quad$ Cyclooxygenase (5 pathways)

- Ether-a-go-go voltage gated potassium channel

- Glucocorticoid Receptor (2 pathways)

- Glutamate Receptor

- Histamine H2 Receptor

- $\quad$ Serotonin Transporter (2 pathways)

- $\quad$ Sodium Channel (3 pathways) 
This shows much promise for the future of AOP-based toxicology studies, as the AOP Wiki is currently in its infancy and will continue to grow over time, providing further scope for the identification of potentially toxic pathways using work such as this.

One pathway from the AOP wiki is well developed for agonism of the androgen receptor leading to reproductive dysfunction in adult female fish. While this pathway is not based on human toxicology studies, with time the AOP Wiki will be able to provide such detailed pathways for human toxicity pathways. In addition to this there are a number of MIEs, KEs and AOPs that transcend species and as such this research may be relevant to human toxicology. In essence agonism at the androgen receptor leads to a decrease in the concentrations of the hormones gonadotropin, testosterone, estradiol and vitellogenin. A decrease in vitellogenin uptake leads to impaired development of oocytes, decreased spawning rates and a population decline. A graphic of this AOP is shown in Figure 2.

Further information on clinical pathways that may be affected by the agonism or antagonism of the targets studied in this work is presented in the Bowes 2012 article. $^{18}$

\section{CONCLUSIONS}

As toxicology moves away from animal based approaches and towards in silico and in vitro methods, further understanding and new tools are required. The MIE is the first KE in the AOP, the boundary between chemistry and biology where a chemical makes its first key interaction with the body. By understanding the chemical properties of existing receptor-binding chemicals we aim to be able to predict the MIEs of new molecules computationally. The focus of this work 
was to utilize open source data to develop 2D structural alert-based SAR models for the prediction of MIEs associated with pharmacologically important human targets.

We have produced a number of 2D SAR models in an attempt to describe the characteristic fragments that allow molecules to cause effects via MIEs. A total of 126 alerts across 45 human targets have been developed in this work. A number of these alerts performed well, with an emphasis on being able to combine alerts into models for individual targets which will have high levels of specificity and therefore will not over-fire. When the 45 combined models were tested, 29 models scored sensitivity values of $50 \%$ or more, 13 scored $75 \%$ or more and five scored $90 \%$ or more, providing overall a good level of coverage. To prevent the models over-firing the whole ChEMBL data set was analyzed to provide fragments that are common in chemicals in this set, and as such should not be used as structural alerts. This information was used, along with existing pharmacophores, crystal structures and an understanding of typical binders found in the literature, to manually curate structural alerts provided by a maximal common substructure searches and develop structural alerts. This has resulted in a number of structural alerts with high specificity values: 95 of 126 alerts scored $95 \%$ or greater specificity values.

Understanding of the chemical characteristics that govern receptor MIEs will be a key step in the development of AOP based tools for toxicity risk assessment. 2D fragment based approaches are not the only way to attempt to answer this complex problem, and a number of approaches will need to be combined to provide a quantitative risk assessment. In this first step we have begun to explore this area, with sights set on the development of in silico screening tools. We believe that these fragment alerts can provide useful information in compound development, regarding the potential toxic effects of lead chemical compounds, and provide a basis for exciting new developments in the understanding of receptor MIEs, and how they can be used in toxicology. 


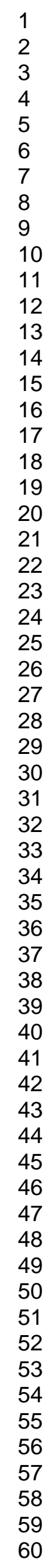

ACS Paragon Plus Environment 


\title{
ASSOCIATED CONTENT
}

\section{Supporting Information.}

SMARTS/SMILES for the structural alerts developed in this work. This material is available free of charge via the Internet at http://pubs.acs.org.

\section{AUTHOR INFORMATION}

\section{Corresponding Author}

jmg11@cam.ac.uk

\author{
Author Contributions \\ The manuscript was written through contributions of all authors. All authors have given approval \\ to the final version of the manuscript.
}

\section{Funding Sources}

The authors acknowledge the financial support of Unilever.

\section{Data Statement}

According to the University of Cambridge data management policy, all the data used in this paper is available either in the paper or in the SI. A copy of the data is also available in the University of Cambridge repository at: https:/www.repository.cam.ac.uk/

\section{ABBREVIATIONS}


AA2aR, adenosine A2a receptor; AC, acetylcholinesterase; ADR, adrenergic receptor; AOP, adverse outcome pathway; AR, androgen receptor; CCKAR, cholecystokinin A receptor; COX, cyclooxygenase; CR, cannabinoid receptor; DHFR, dihydrofolate reductase; DR, dopamine receptor; DT, dopamine transporter; E2, estradiol; ER ET-A, endothelin receptor ET-A; GART, GAR transformylase; GPCR, G-protein coupled receptor; GR, glucocorticoid receptor; GRSZ1, glutamate receptor subunit zeta 1; GtH, gonadotropin hormone; HDAC 1, histone deacetylase 1; HERG; human ether-a-go-go related gene; HR, histamine receptor; LCK, tyrosin protein kinase; MAO A, monoamine oxidase A; MAR, muscarinic acetylcholine receptor; MCC, Matthews correlation coefficient; MIE, molecular initiating event; MOB, mode of binding; NMDA, Nmethyl-D-aspartate; NT, norepinephrine transporter; OR, opioid receptor; PDE, phosphoidesterase; Q, overall quality; (Q)SAR, (quantitative)structure activity relationship; SCV-A, sodium channel V subunit alpha; SE, sensitivity; SP, specificity; SR, serotonin receptor; $\mathrm{ST}$, serotonin transporter; T, testosterone; TS, thymidylate synthase; VGKC Kv7.1, voltage gated K channel subunit Kv7.1; VTG, vitellogenin; VV1a, vasopressin V1a.

\section{REFERENCES}

(1) Allen, T. E. H., Goodman, J. M., Gutsell, S., and Russell, P. J. (2014) Defining molecular initiating events in the adverse outcome pathway framework for risk assessment. Chem. Res. Toxicol. 27, 2100-2112.

(2) Gutsell, S., and Russell, P. (2013) The role of chemistry in developing understanding of adverse outcome pathways and their application in risk assessment. Toxicol. Res. 2, 299-307.

(3) OECD. Proposal for a Template, and Guidance on Developing and Assessing the Completeness of Adverse Outcome Pathways, Appendix I, Collection of Working Definitions. http:/www.oecd.org/chemicalsafety/testingofchemicals/49963576.pdf.

(4) Ankley, G. T., Bennett, R. S., Erickson, R. J., Hoff, D. J., Hornung, M. W., Johnson, R. D., Mount, D. R., Nichols, J. W., Russom, C. L., Schmieder, P. K., Serrrano, J. A., Tietge, J. E., and Villeneuve, D. L. (2010) Adverse outcome pathways: A conceptual framework to support ecotoxicology research and risk assessment. Environ. Toxicol. Chem. 29, 730-741.

(5) Committee on Toxicity Testing and Assessment of Environmental Agents and National Research Council. (2007) Toxicology testing in the 21st century: A vision and a strategy, National Academies Press, Washington, DC. 
(6) Hartung, T. (2009) A Toxicology for the 21st Century-Mapping the Road Ahead. Toxicol. Sci. 109, 18-23.

(7) Burden, N., Sewell, F., Andersen, M. E., Boobis, A., Chipman, J. K., Cronin, M. T. D., Hutchinson, T. H., Kimber, I., and Whelan, M. (2015) Adverse Outcome Pathways can drive non-animal approaches for safety assessment. J. Appl. Toxicol. 35, 971-975.

(8) Yang, C., Arvidson, K., Richard, A., Worth, A., Tarkhov, A., Ringeissen, S., Marusczyk, J., Gasteiger, J., Rathman, J., and Schwab, C. (2014) Chemotypes and chemotyper: A new structural representation standard to include atomic/bond properties into structural alerts for toxicity effects and mechanisms, http://www.epa.gov/ncct/download files/sot/posters/2013/SOT2013_poster_Chemotype_final.pdf.

(9) Nelms, M. D., Ates, G., Madden, J. C., Vinken, M., Cronin, M. T. D., Rogiers, V., and Enoch, S. J. (2014) Proposal of an in silico profiler for categorisation of repeat dose toxicity data of hair dyes. Arch. Toxicol. 89, 733-741.

(10) Tsakovska, I., Al Sharif, M., Alov, P., Diukendjieva, A., Fioravanzo, E., Cronin, M. T. D., and Pajeva, I. (2014) Molecular modelling study of the PPAR $\gamma$ receptor in relation to the mode of action/adverse outcome pathway framework for liver steatosis. Int. J. Mol. Sci. 15, 76517666.

(11) Cherkasov, A., Muratov, E. N., Fourches, D., Varnek, A., Baskin, I. I., Cronin, M., Dearden, J., Gramatica, P., Martin, Y. C., Todeschini, R., Consonni, V., Kuz'min, V. E., Cramer, R., Benigni, R., Yang, C., Rathman, J., Terfloth, L., Gasteiger, J., Richard, A., and Tropsha, A. (2014) QSAR modeling: Where have you been? Where are you going to? J. Med. Chem. 57, 4977-5010.

(12) McKinney, J. D., Richard, A., Waller, C., Newman, M. C., and Gerberick, F. (2000) The practice of structure activity relationships (SAR) in toxicology. Toxicol. Sci. 56, 8-17.

(13) Payne, M. P., and Walsh, P. T. (1994) Structure-activity relationships for skin sensitization potential: development of structural alerts for use in knowledge-based toxicity prediction systems. J. Chem. Inf. Comput. Sci. 34, 154-161.

(14) Marchant, C. A., Briggs, K. A., and Long, A. (2008) In Silico Tools for Sharing Data and Knowledge on Toxicity and Metabolism: Derek for Windows, Meteor, and Vitic. Toxicol. Mech. Methods 18, 177-187.

(15) The OECD QSAR Toolbox, http://www.qsartoolbox.org/.

(16) Madden, J. C., Rogiers, V., and Vinken, M. (2014) Application of in silico and in vitro methods in the development of adverse outcome pathway constructs in wildlife. Philos. Trans. $R$. Soc. B Biol. Sci. 369, 1-7.

(17) Tollefsen, K. E., Scholz, S., Cronin, M. T., Edwards, S. W., de Knecht, J., Crofton, K., Garcia-Reyero, N., Hartung, T., Worth, A., and Patlewicz, G. (2014) Applying Adverse Outcome Pathways (AOPs) to support Integrated Approaches to Testing and Assessment (IATA). Regul. Toxicol. Pharmacol. 70, 629-640.

(18) Bowes, J., Brown, A. J., Hamon, J., Jarolimek, W., Sridhar, A., Waldron, G., and Whitebread, S. (2012) Reducing safety-related drug attrition: the use of in vitro pharmacological profiling. Nat. Rev. Drug Discov. 11, 909-22.

(19) Schwöbel, J. A. H., Koleva, Y. K., Enoch, S. J., Bajot, F., Hewitt, M., Madden, J. C., 
Roberts, D. W., Schultz, T. W., and Cronin, M. T. D. (2011) Measurement and estimation of electrophilic reactivity for predictive toxicology. Chem. Rev. 111, 2562-2596.

(20) Bento, A. P., Gaulton, A., Hersey, A., Bellis, L. J., Chambers, J., Davies, M., Krüger, F. A., Light, Y., Mak, L., McGlinchey, S., Nowotka, M., Papadatos, G., Santos, R., and Overington, J. P. (2014) The ChEMBL bioactivity database: An update. Nucleic Acids Res. 42, 1083-1090.

(21) European Molecular Biology Laboratory-European Bioinformatics Institute, ChEMBL database, https://www.ebi.ac.uk/chembl/.

(22) Accelrys Software Inc. Pipeline Pilot v.8.0.1.500.

(23) Matthews, B. W. (1975) Comparison of the Predicted and Observed Secondary Structure of T4 Phage Lysozyme. Biochim. Biophys. Acta 405, 442-451.

(24) European Commission Institute for Health and Consumer Protection. AOP Wiki, https://aopkb.org/aopwiki/index.php/Main_Page.

(25) Park, H. M., Lee, J. H., Yaoyao, J., Jun, H. J., and Lee, S. J. (2011) Limonene, a natural cyclic terpene, is an agonistic ligand for adenosine A2A receptors. Biochem. Biophys. Res. Commun. 404, 345-348.

(26) Russo, C., Arcidiacono, G., and Polosa, R. (2006) Adenosine receptors: Promising targets for the development of novel therapeutics and diagnostics for asthma. Fundam. Clin. Pharmacol. 20,9-19.

(27) Hodgson, R. A., Bertorelli, R., Varty, G. B., Lachowicz, J. E., Forlani, A., Fredduzzi, S., Cohen-williams, M. E., Higgins, G. A., Impagnatiello, F., Nicolussi, E., Parra, L. E., Foster, C., Zhai, Y., Neustadt, B. R., Stamford, A. W., Parker, E. M., Reggiani, A., and Hunter, J. C. (2009) Characterization of the potent and highly selective A2A receptor antagonists preladenant and SCH 412348 [7-[2-[4- 2,4-Difluorophenyl]-1-piperazinyl]ethyl]-2-(2-furanyl)-7H- pyrazolo[4,3e] $[1,2,4]$ triazolo[1,5-c]pyrimidin-5-amine] in rodent models of moveme. J. Pharmacol. Exp. Ther. 330, 294-303.

(28) Bylund, D. B. (1985) Heterogeneity of alpha-2 adrenergic receptors. Pharmacol. Biochem. Behav. 22, 835-843.

(29) Sanders, J., Miller, D. D., and Patil, P. N. (1975) Alpha adrenergic and histaminergic effects of tolazoline-like imidazolines. J. Pharmacol. Exp. Ther. 195, 362-371.

(30) Knepper, S. M., Buckner, S. A., Brune, M. E., DeBernardis, J. F., Meyer, M. D., and Hancock, A. A. (1995) A-61 603 , a potent alpha1-adrenergic receptor agonist, selective for the alpha1A receptor subtype. J. Pharmacol. Exp. Ther. 274, 97-103.

(31) Li, G., Regunathan, S., Barrow, C. J., Eshraghi, J., Cooper, R., and Reis, D. J. (1994) Agmatine: an endogenous clonidine-displacing substance in the brain. Science (80-. ). 263, 966969.

(32) Lemke, K. A. (2004) Perioperative use of selective alpha-2 agonists and antagonists in small animals. Can. Vet. J. 45, 475-480.

(33) Angeli, P., Volpin, R., Piovan, D., Bortoluzzi, A., Craighero, R., Bottaro, S., Finucci, G. F., Casiglia, E., Sticca, A., De Toni, R., Pavan, L., and Gatta, A. (1998) Acute effects of the oral administration of midodrine, an alpha-adrenergic agonist, on renal hemodynamics and renal function in cirrhotic patients with ascites. Hepatology 28, 937-943. 
(34) Wellman, P. J., and Davies, B. T. (1992) Reversal of cirazoline- and phenylpropanolamineinduced anorexia by the alpha 1-receptor antagonist prazosin. Pharmacol. Biochem. Behav. 42, 97-100.

(35) Lasch, P., and Jakobs, K. H. (1979) Agonistic and antagonistic effects of various alphaadrenergic agonists in human platelets. Naunyn. Schmiedebergs. Arch. Pharmacol. 306, 119125.

(36) Kier, L. B. (1969) The prefered conformation of noradrenaline and a consideration of the alpha-adrenergic receptor. J. Pharm. Pharmacol. 21, 93-96.

(37) Virtanen, R., Savola, J. M., Saano, V., and Nyman, L. (1988) Characterization of the selectivity, specificity and potency of medetomidine as an alpha 2-adrenoceptor agonist. Eur. $J$. Pharmacol. 150, 9-14.

(38) Arnsten, A. F., Cai, J. X., and Goldman-Rakic, P. S. (1988) The alpha-2 adrenergic agonist guanfacine improves memory in aged monkeys without sedative or hypotensive side effects: evidence for alpha-2 receptor subtypes. J. Neurosci. 8, 4287-4298.

(39) Tang, C., Biemond, I., and Lamers, C. B. (1996) Cholecystokinin receptors in human pancreas and gallbladder muscle: a comparative study. Gastroenterology 111, 1621-1626.

(40) Feinle, C., Meier, O., Otto, B., D’Amato, M., and Fried, M. (2001) Role of duodenal lipid and cholecystokinin A receptors in the pathophysiology of functional dyspepsia. Gut 48, 347355.

(41) Eberle-Wang, K., and Simansky, K. J. (1992) The CCK-A receptor antagonist, devazepide, blocks the anorectic action of CCK but no peripheral serotonin in rats. Pharmacol. Biochem. Behav. 43, 943-947.

(42) Zhang, J., Xiong, B., Zhen, X., and Zhang, A. (2008) Dopamine D1 receptor ligands: where are we now and where are we going. Med. Res. Rev. 29, 272-294.

(43) Ishizuka, N., and Matsumura, K. (2002) Structure-activity relationships of a novel class of endothelin-A receptor antagonists and discovery of potent and selective receptor antagonist, 2(benzo[1,3]dioxol-5-yl)-6-isopropyloxy-4-(4-methoxyphenyl)-2H-chromene-3- carboxylic acid (S-1255). 1. Stud. J. Med. Chem. 45, 2041-2055.

(44) Shimamura, T., Shiroishi, M., Weyand, S., Tsujimoto, H., Winter, G., Katritch, V., Abagyan, R., Cherezov, V., Liu, W., Han, G. W., Kobayashi, T., Stevens, R. C., and Iwata, S. (2011) Structure of the human histamine H1 receptor complex with doxepin. Nature 475, 65-70.

(45) Langmead, C. J., Austin, N. E., Branch, C. L., Brown, J. T., Buchanan, K. A., Davies, C. H., Forbes, I. T., Fry, V. A. H., Hagan, J. J., Herdon, H. J., Jones, G. A., Jeggo, R., Kew, J. N. C., Mazzali, A., Melarange, R., Patel, N., Pardoe, J., Randall, A. D., Roberts, C., Roopun, A., Starr, K. R., Teriakidis, A., Wood, M. D., Whittington, M., Wu, Z., and Watson, J. (2008) Characterization of a CNS penetrant, selective M1 muscarinic receptor agonist, 77-LH-28-1. $\mathrm{Br}$. J. Pharmacol. 154, 1104-1115.

(46) Vannucchi, M. G., Scali, C., Kopf, S. R., Pepeu, G., and Casamenti, F. (1997) Selective muscarinic antagonists differentially affect in vivo acetylcholine release and memory performances of young and aged rats. Neuroscience 79, 837-846.

(47) Baghdoyan, H. A., and Lydic, R. (1999) M2 muscarinic receptor subtype in the feline medial pontine reticular formation modulates the amount of rapid eye movement sleep. Sleep 22, 
$835-847$.

(48) Slack, B. E., Breu, J., Petryniak, M. A., Srivastava, K., and Wurtman, R. J. (1995) Tyrosine phosphorylation-dependent stimulation of amyloid precursor protein secretion by the $\mathrm{m} 3$ muscarinic acetylcholine receptor. J. Biol. Chem. 270, 8337-8344.

(49) Haga, K., Kruse, A. C., Asada, H., Yurugi-Kobayashi, T., Shiroishi, M., Zhang, C., Weis, W. I., Okada, T., Kobilka, B. K., Haga, T., and Kobayashi, T. (2012) Structure of the human M2 muscarinic acetylcholine receptor bound to an antagonist. Nature 482, 547-551.

(50) Manglik, A., Kruse, A. C., Kobilka, T. S., Thian, F. S., Mathiesen, J. M., Sunahara, R. K., Pardo, L., Weis, W. I., Kobilka, B. K., and Granier, S. (2012) Crystal structure of the $\mu$-opioid receptor bound to a morphinan antagonist. Nature 485, 321-326.

(51) Lemmens-Gruber, R., and Kamyar, M. (2006) Vasopressin antagonists. Cell. Mol. Life Sci. 63, 1766-1779.

(52) Serradeil-Le Gal, C., Wagnon, J., Garcia, C., Lacour, C., Guiraudou, P., Christophe, B., Villanova, G., Nisato, D., Maffrand, J. P., Le Fur, G., Guillon, G., Cantau, B., Barberis, C., Trueba, M., Ala, Y., and Jard, S. (1993) Biochemical and pharmacological properties of SR 49059, a new, potent, nonpeptide antagonist of rat and human vasopressin V1a receptors. J. Clin. Invest. 92, 224-231.

(53) Guillon, C. D., Koppel, G. A., Brownstein, M. J., Chaney, M. O., Ferris, C. F., Lu, S. F., Fabio, K. M., Miller, M. J., Heindel, N. D., Hunden, D. C., Cooper, R. D. G., Kaldor, S. W., Skelton, J. J., Dressman, B. A., Clay, M. P., Steinberg, M. I., Bruns, R. F., and Simon, N. G. (2007) Azetidinones as vasopressin V1a antagonists. Bioorganic Med. Chem. 15, 2054-2080.

(54) Akaike, A., Takada-Takatori, Y., Kume, T., and Izumi, Y. (2010) Mechanisms of neuroprotective effects of nicotine and acetylcholinesterase inhibitors: Role of $\alpha 4$ and $\alpha 7$ receptors in neuroprotection. J. Mol. Neurosci. 40, 211-216.

(55) Hawser, S., Lociuro, S., and Islam, K. (2006) Dihydrofolate reductase inhibitors as antibacterial agents. Biochem. Pharmacol. 71, 941-948.

(56) Oefner, C., D’Arcy, A., and Winkler, F. K. (1988) Crystal structure of human dihydrofolate reductase complexed with folate. Eur. J. Biochem. 174, 377-385.

(57) Miller, T. A., Witter, D. J., and Belvedere, S. (2003) Histone deacetylase inhibitors. J. Med. Chem. 46, 5097-5116.

(58) Villar-Garea, A., and Esteller, M. (2004) Histone deacetylase inhibitors: understanding a new wave of anticancer agents. Int. J. Cancer 112, 171-178.

(59) Wouters, J., Moureau, F., Evrard, G., Koenig, J. J., Jegham, S., George, P., and Durant, F. (1999) A reversible monoamine oxidase a inhibitor, befloxatone: Structural approach of its mechanism of action. Bioorganic Med. Chem. 7, 1683-1693.

(60) Kan, J. P., Mouget-Goniot, C., Worms, P., and Biziere, K. (1986) Effect of the antidepressant minaprine on both forms of monoamine oxidase in the rat. Biochem. Pharmacol. $35,973-978$.

(61) Lee, M. E., Markowitz, J., Lee, J. O., and Lee, H. (2002) Crystal structure of phosphodiesterase 4D and inhibitor complex. FEBS Lett. 530, 53-58.

(62) Touroutoglou, N., and Pazdur, R. (1996) Thymidylate synthase inhibitors. Clin. Cancer Res. 
2, 227-243.

(63) Lee, K. C., Ouwehand, I., Giannini, A. L., Thomas, N. S., Dibb, N. J., and Bijlmakers, M. J. (2010) Lck is a key target of imatinib and dasatinib in T-cell activation. Leukemia 24, 896-900.

(64) Waldhauser, K. M., Brecht, K., Hebeisen, S., Ha, H. R., Konrad, D., Bur, D., and Krähenbühl, S. (2008) Interaction with the hERG channel and cytotoxicity of amiodarone and amiodarone analogues. Br. J. Pharmacol. 155, 585-595.

(65) Pearlstein, R. A., Vaz, R. J., Kang, J., Chen, X. L., Preobrazhenskaya, M., Shchekotikhin, A. E., Korolev, A. M., Lysenkova, L. N., Miroshnikova, O. V., Hendrix, J., and Rampe, D. (2003) Characterization of HERG potassium channel inhibition using CoMSiA 3D QSAR and homology modeling approaches. Bioorganic Med. Chem. Lett. 13, 1829-1835.

(66) Ekins, S., Crumb, W. J., Sarazan, R. D., Wikel, J. H., and Wrighton, S. A. (2002) Threedimensional quantitative structure-activity relationship for inhibition of human ether-a-go-gorelated gene potassium channel. J. Pharmacol. Exp. Ther. 301, 427-434.

(67) Cavalli, A., Poluzzi, E., De Ponti, F., and Recanatini, M. (2002) Toward a pharmacophore for drugs inducing the long QT syndrome: Insights from a CoMFA study of HERG K+ channel blockers. J. Med. Chem. 45, 3844-3853.

(68) Kelley, S. P., Bratt, A. M., and Hodge, C. W. (2003) Targeted gene deletion of the 5-HT3A receptor subunit produces an anxiolytic phenotype in mice. Eur. J. Pharmacol. 461, 19-25.

(69) Mørk, A., Montezinho, L. P., Miller, S., Trippodi-Murphy, C., Plath, N., Li, Y., Gulinello, M., and Sanchez, C. (2013) Vortioxetine (Lu AA21004), a novel multimodal antidepressant, enhances memory in rats. Pharmacol. Biochem. Behav. 105, 41-50.

(70) Matias, P. M., Donner, P., Coelho, R., Thomaz, M., Peixoto, C., Macedo, S., Otto, N., Joschko, S., Scholz, P., Wegg, A., Bäsler, S., Schäfer, M., Egner, U., and Carrondo, M. A. (2000) Structural evidence for ligand specificity in the binding domain of the human androgen receptor. Implications for pathogenic gene mutations. J. Biol. Chem. 275, 26164-26171.

(71) Veldscholte, J., Berrevoets, C. A., Brinkmann, A. O., Grootegoed, J. A., and Mulder, E. (1992) Anti-androgens and the mutated androgen receptor of LNCaP cells: differential effects on binding affinity, heat-shock protein interaction, and transcription activation. Biochemistry 31, 2393-2399.

(72) Simard, J., Luthy, I., Guay, J., Bélanger, A., and Labrie, F. (1986) Characteristics of interaction of the antiandrogen flutamide with the androgen receptor in various target tissues. Mol. Cell. Endocrinol. 44, 261-270.

(73) Bledsoe, R. K., Montana, V. G., Stanley, T. B., Delves, C. J., Apolito, C. J., McKee, D. D., Consler, T. G., Parks, D. J., Stewart, E. L., Willson, T. M., Lambert, M. H., Moore, J. T., Pearce, K. H., and $\mathrm{Xu}, \mathrm{H}$. E. (2002) Crystal structure of the glucocorticoid receptor ligand binding domain reveals a novel mode of receptor dimerization and coactivator recognition. Cell 110, 93105.

(74) Oomen, C. A., Mayer, J. L., De Kloet, E. R., Joëls, M., and Lucassen, P. J. (2007) Brief treatment with the glucocorticoid receptor antagonist mifepristone normalizes the reduction in neurogenesis after chronic stress. Eur. J. Neurosci. 26, 3395-3401.

(75) Honer, C., Nam, K., Fink, C., Marshall, P., Ksander, G., Chatelain, R. E., Cornell, W., Steele, R., Schweitzer, R., and Schumacher, C. (2003) Glucocorticoid receptor antagonism by 
cyproterone acetate and RU486. Mol. Pharmacol. 63, 1012-1020.

(76) Ritz, M. C., Cone, E. J., and Kuhar, M. J. (1990) Cocaine inhibition of ligand binding at dopamine, norepinephrine and serotonin transporters: a structure-activity study. Life Sci. 46, 635-645.

(77) Carroll, F. I., Lewin, A. H., Boja, J. W., and Kuhar, M. J. (1992) Cocaine receptor: biochemical characterization and structure-activity relationships of cocaine analogues at the dopamine transporter. J. Med. Chem. 35, 969-981.

(78) Beuming, T., Kniazeff, J., Bergmann, M. L., Shi, L., Gracia, L., Raniszewska, K., Newman, A. H., Javitch, J. A., Weinstein, H., Gether, U., and Loland, C. J. (2008) The binding sites for cocaine and dopamine in the dopamine transporter overlap. Nat. Neurosci. 11, 780-789.

(79) Florin, S. M., Kuczenski, R., and Segal, D. S. (1994) Regional extracellular norepinephrine responses to amphetamine and cocaine and effects of clonidine pretreatment. Brain Res. 654, 5362.

(80) Segonzac, A., Raisman, R., Tateishi, T., Schoemaker, H., Hicks, P. E., and Langer, S. Z. (1985) Tryptamine, a substrate for the serotonin transporter in human platelets, modifies the dissociation kinetics of $[3 \mathrm{H}]$ imipramine binding: Possible allosteric interaction. J. Neurochem. 44, 349-356. 


\section{$\underline{\text { FIGURES }}$}

Figure 1A
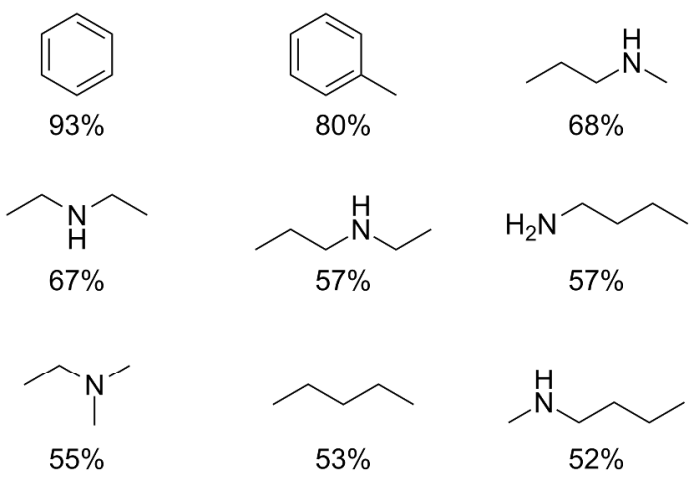

Figure 1B
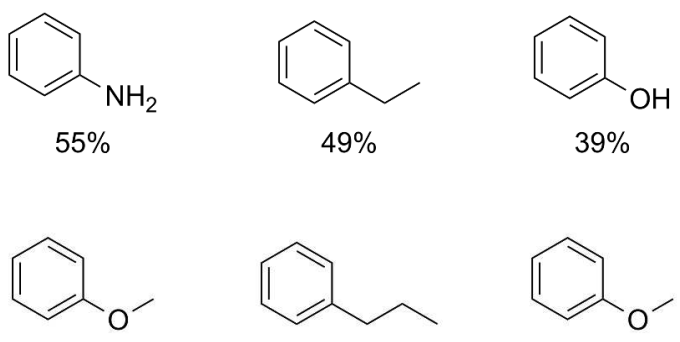

$33 \%$

$30 \%$

$33 \%$

Figure 1C

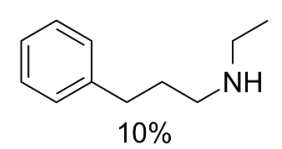

Figure 1. 2D fragments common within the entire dataset for this study. Part 1A shows fragments larger than four chemical bonds present within $50 \%$ or greater of the data set. Part $1 \mathrm{~B}$ shows fragments larger than seven chemical bonds present within $30 \%$ or greater of the data set. Part $1 \mathrm{C}$ shows fragments larger than 12 chemical bonds present within $10 \%$ or greater of the data set. 


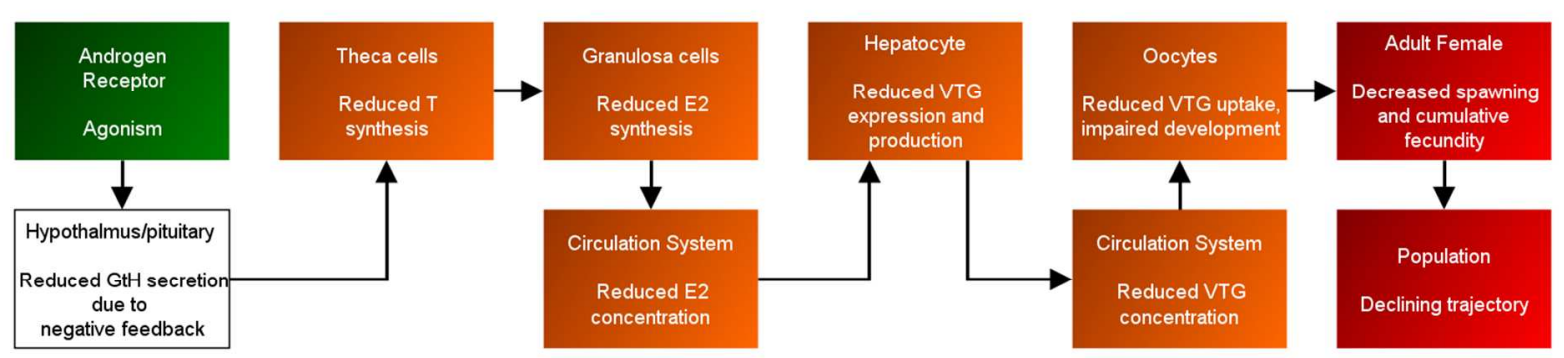

Figure 2. AOP for androgen receptor agonism leading to reproductive dysfunction. The MIE is shown in green, KEs in orange and adverse outcomes in red as per the AOP Wiki template. Reduced GtH secretion in the hypothalamus/pituitary is shown in white as there is uncertainty as to the specific mechanism through which androgen receptor agonism elicits a negative feedback response at this key event. E2: estradiol, GtH: gonadotropin hormone, T: testosterone, VTG: vitellogenin. 


\section{$\underline{\text { TABLES }}$}

Target

G-Protein Coupled Receptors

Adenosine A2a Receptor

Alpha-1a Adrenergic Receptor

Alpha-2a Adrenergic Receptor

Beta-1 Adrenergic Receptor

Beta-2 Adrenergic Receptor

Cannabinoid CB1 Receptor

Cannabinoid CB2 Receptor

Cholecystokinin Receptor A

Dopamine D1 Receptor

Dopamine D2 Receptor

Endothelin Receptor A

Histamine H1 Receptor

Histamine H2 Receptor

Muscarinic Acetylcholine Receptor M1

Muscarinic Acetylcholine Receptor M2

Muscarinic Acetylcholine Receptor M3

Delta Opioid Receptor

Kappa Opioid Receptor

Mu Opioid Receptor

Serotonin 1A Receptor

Serotonin 1B Receptor

Serotonin 2A Receptor

Serotonin 2B Receptor

Vasopressin V1A Receptor

\begin{tabular}{|c|c|c|c|}
\hline Binders & $\begin{array}{c}\text { Binders } \\
\text { Training } \\
\text { Set }\end{array}$ & $\begin{array}{l}\text { Binders } \\
\text { Test Set } \\
\text { (positive) }\end{array}$ & $\begin{array}{c}\text { Test Set } \\
\text { (negative) }\end{array}$ \\
\hline 2960 & 2150 & 810 & 10820 \\
\hline 705 & 510 & 195 & 11435 \\
\hline 380 & 269 & 111 & 11519 \\
\hline 694 & 505 & 189 & 11441 \\
\hline 770 & 540 & 230 & 11400 \\
\hline 3738 & 2688 & 1050 & 10580 \\
\hline 3405 & 2435 & 970 & 10660 \\
\hline 255 & 177 & 78 & 11552 \\
\hline 453 & 322 & 131 & 11499 \\
\hline 2589 & 1831 & 758 & 10872 \\
\hline 100 & 72 & 28 & 11602 \\
\hline 672 & 499 & 173 & 11457 \\
\hline 191 & 141 & 50 & 11580 \\
\hline 887 & 639 & 248 & 11382 \\
\hline 620 & 456 & 164 & 11466 \\
\hline 1067 & 772 & 295 & 11335 \\
\hline 2550 & 1657 & 893 & 10737 \\
\hline 2347 & 1721 & 626 & 11004 \\
\hline 2793 & 2056 & 737 & 10893 \\
\hline 1777 & 1273 & 504 & 11126 \\
\hline 396 & 282 & 114 & 11516 \\
\hline 1612 & 1162 & 450 & 11180 \\
\hline 750 & 555 & 195 & 11435 \\
\hline 651 & 471 & 180 & 11450 \\
\hline
\end{tabular}




\section{Enzymes}

Acetylcholinesterase

1355

989

366

11264

Cyclooxygenase 1

379

274

105

11525

Cyclooxygenase 2

964

686

278

11352

Dihydrofolate Reductase

404

294

110

11520

GAR Transformylase

36

23

13

11617

Histone Deacetylase 1

1202

882

320

11310

Monoamine Oxidase A

533

382

151

11479

Phosphodiesterase 3A

132

94

38

11592

Phosphodiesterase 4D

385

267

118

11512

Thymidylate Synthase

239

178

61

11569

Tyrosine-Protein Kinase

568

414

154

11476

Ion Channels

Glutamate (NMDA) Receptor

25

18

7

11623

Potassium Voltage Gated Channel KQT-like Member 1

295

215

80

11550

Serotonin 3A Receptor

316

230

86

11544

Sodium Channel V Subunit Alpha

153

111

42

11588

Voltage Gated K Channel Subunit Kv7.1

28

21

7

11623

\section{Nuclear Receptors}

Androgen Receptor

1598

1186

412

11218

Glucocorticoid Receptor

2201

1622

579

11051 
Transporters

$\begin{array}{lllll}\text { Dopamine Transporter } & 1908 & 1414 & 494 & 11136\end{array}$

$\begin{array}{lllll}\text { Norepinephrine Transporter } & 2616 & 1923 & 693 & 10937\end{array}$

$\begin{array}{lllll}\text { Serotonin Transporter } & 3480 & 2578 & 902 & 10728\end{array}$

Table 1. Pharmacological targets analyzed in this work. Data was extracted from ChEMBL version 19. The total test set in each case was 11630 compounds. 


\section{G-Protein Coupled Receptors}

\section{${ }_{Q}$ Adenosine A2a Receptor}

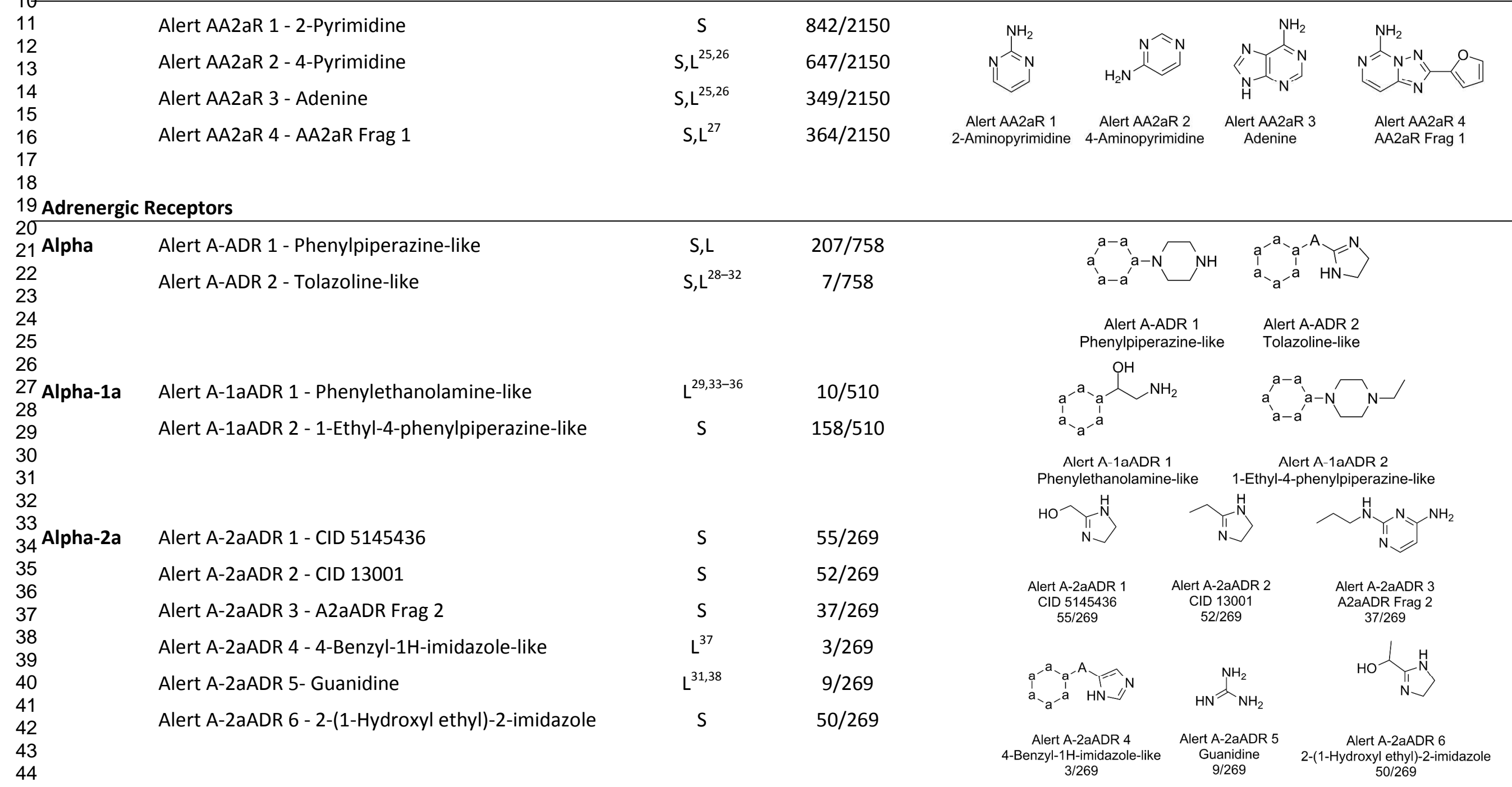


33 Cholecystokinin A Receptor

Origin

Alert B-ADR 1 - 1-(Phenethylamino)propan-2-ol-like

Alert B-ADR 2 - 2-(Ethylamino)-1-phenylethanol-like

Alert B-ADR 3 - 1-(Ethylamino)-3-phenoxyl-2propanol-like

\section{$\mathrm{S}$}

$\mathrm{S}$

$S$
$\mathrm{S}$

Alert CCB1R 1 - 2-Phenylpyrazole-like

Alert CCB1R 2 - 5-Phenyl-1H-pyrazole-like

Alert CCB1R 3 - Pyrazole-3-carboxamide

Alert CCB2R 1 - CCB2R Frag 1

Alert CCB2R 2 - 1-(1-Ethyl-1H-pyrrol-3-yl)ethanone

CB1 \& CB2 Alert CR 1 - Indole
Alerts

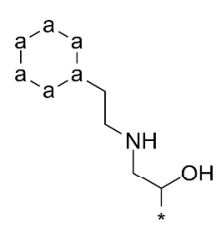
-(Phenethylamino)
Alert B-ADR 1

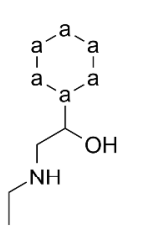

Alert B-ADR 2 2-(Ethylamino)-1

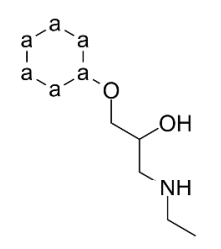

Alert B-ADR 3 -(Ethylamino)-3-Phenoxy-2propanol-like
Alert CCKAR 1 - 2-Acetamido-N-methylacetamide Alert CCKAR 2 - N-[2-(methylamino)ethyl]acetamide Alert CCKAR 3 - CID 9957635

$\begin{array}{cc}\mathrm{S}, \mathrm{L}^{39-41} & 72 / 177 \\ \mathrm{~S}, \mathrm{~L}^{39-41} & 159 / 177 \\ \mathrm{~S} & 63 / 177\end{array}$

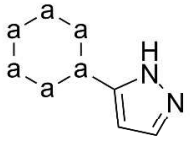

Alert CCB1R 2

Alert CCB1R 1 2-Phenylpyrazole-like 5-Phenyl-1H-pyrazole-like

$298 / 2435$

$217 / 2435$

$489 / 3362$

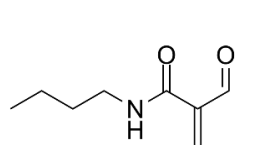

Alert CCB2R 1 CCB2R Frag 1

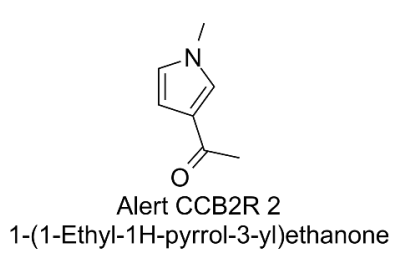

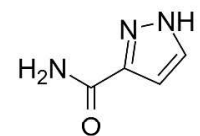

Alert CCB1R 3 Pyrazole-3-carboxamide

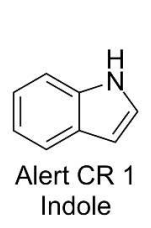


Alert DD1R 1 - Dihydrexine-like

Alert DD1R 2 - Benzazepine-like

Alert DD1R 3 - Benzazepine-like with aromatic

Alert DD1R 4 - CID 15288

Alert DD2R 1 - Piperazine

Alert DD2R 2 - 1,4 Dimethylpiperazine

Alert DD2R 3 - Phenylpiperazine

$\begin{array}{cc}\mathrm{L}^{42} & 21 / 322 \\ \mathrm{~L}^{42} & 20 / 322 \\ \mathrm{~L}^{42} & 19 / 322 \\ \mathrm{~S} & 84 / 322 \\ & \\ \mathrm{~S} & 1006 / 1831 \\ \mathrm{~S} & 1000 / 1831 \\ \mathrm{~S} & 727 / 1831\end{array}$
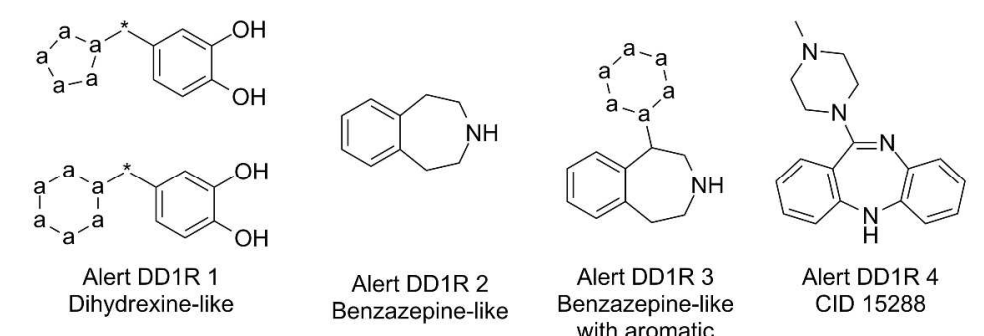

Dihydrexine-like

Alert DD1R 2 Benzazepine-like

Alert DD1R 3 with aromatic Alert DD1R 4 CID 15288

$$
\overbrace{\mathrm{NH}}
$$
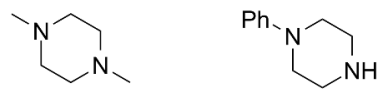

Alert DD2R 1

Alert DD2R 2

Alert DD2R 3

Piperazine 1,4 Dimethylpiperazine Phenylpiperazine

25 Endothelin Receptor A

Alert ER ET-A 1 - 5-Ethyl-1,3-benzodioxole

Alert ER ET-A 2 - N-Methylbenzenesulfonamide-like Alert ER ET-A 3 - Tryptamine

Alert ER ET-A 4 - ER ET-A Frag 1-like

Alert ER ET-A 5 - N-Methyl-2-biphenylsulfonamide-like

$\begin{array}{cc}S, L^{43} & 23 / 72 \\ S & 53 / 72 \\ S & 25 / 72 \\ S & 30 / 72 \\ S & 25 / 72\end{array}$


Alert HH1R 1 - Doxepine-like

Alert HH1R 2 - 4-Phenoxypiperidine

$\mathrm{S}, \mathrm{X}^{44}$

$58 / 444$

14

15

16

${ }_{18}^{17} \mathrm{H2}$

19

20

21

22

23

24 Muscarinic Acetylcholine Receptors

\section{${ }_{26}^{25}$ M1 and M2 Alert MAR 1 - Formanilide}

27

$2 \varepsilon$

31 
19 Serotonin Receptors

$\begin{array}{lll}\text { Alert OR } 1 \text { - Morphine-like (4 or more) } & \text { X, } \mathrm{P}^{50} & 164 / 1385 \\ \text { Alert OR } 1 \text { - Morphine-like (3 or more) } & \text { X,P } & 459 / 1385\end{array}$

Alert OR 2 - 1-Methyl-4-phenylpiperidine

S $\quad 668 / 1385$

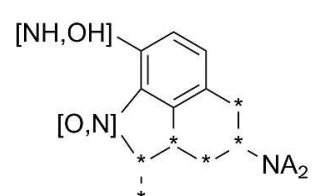

$[\mathrm{OH}, \mathrm{NH}]^{-}$

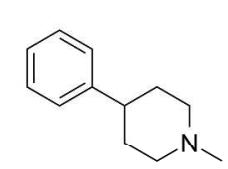

Alert OR 1 Morphine-like 1-Methyl-4-phenylpiperidine 


\section{Vasopressin V1a}

10

11

12

13

14

15

16

17 Enzymes

18
19

20

$$
21
$$

21

23

24

25

\section{Alert VV1a 1 - VV1a Frag 1}

Alert VV1a 2 - n-benzyl-n-ethylmethylamine

Alert VV1a 3 - VV1a Frag 3

Alert VV1a 4 - VV1a Frag 4

$\begin{array}{cc}S, L^{51-53} & 224 / 471 \\ S & 243 / 471 \\ S, L^{51-53} & 187 / 471 \\ S, L^{51-53} & 128 / 471\end{array}$
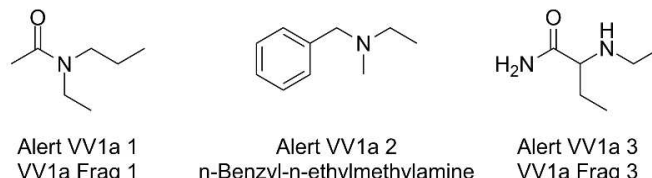
VV1a Frag 1

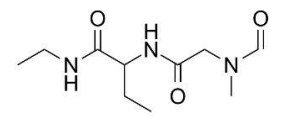

Alert VV1a 4

\section{Acetylcholinesterase}

$\begin{array}{lll}\text { Alert AC 1a - Tacrine } & \mathrm{S}, \mathrm{L}^{54} & 184 / 989 \\ \text { Alert AC 1b - 4-Quinolinamine } & \mathrm{S}, \mathrm{L}^{54} & 192 / 989 \\ \text { Alert AC 1c - AC Frag 1 } & \mathrm{S}, \mathrm{L}^{54} & 245 / 989 \\ \text { Alert AC 1d - Dimethyl benzylamine } & \mathrm{S}, \mathrm{L}^{54} & 395 / 989 \\ \text { Alert AC 1e - Dimethyl benzylamine-like SMARTS } & \mathrm{S}, \mathrm{L}^{54} & 401 / 989\end{array}$

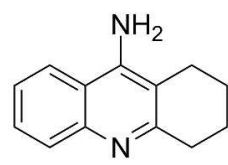

Alert AC 1a Tacrine

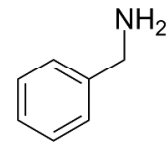

Alert AC 1d

Dimethyl benzylamine

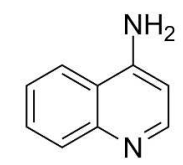

Alert AC 1b 4-Quinolinamine

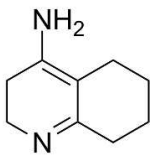

Alert AC 1C AC Frag 1 $\mathrm{NH}_{2}$

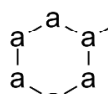

Dimethyl benzylamine-like SMARTS

\section{yclooxygenases}

$\begin{array}{lll}\text { Alert COX } 1 \text { - Sulfonated aromatic rings } & \text { S } & 392 / 816 \\ \text { Alert COX } 2 \text { - Cinnamaldehyde-like } & \mathrm{S} & 183 / 816 \\ \text { Alert COX } 3 \text { - 5-Phenyl-1H-pyrazole-like } & \mathrm{S} & 70 / 816\end{array}$

$$
\begin{aligned}
& a^{-a}-a^{-1}-s_{H}^{O} \\
& \text { a }-a^{-a} \\
& \text { Alert COX }
\end{aligned}
$$

$$
\underset{\substack{a \\ 1 \\ a_{-}-a \\-a}}{a} \curvearrowright 0
$$

Alert COX 2
Cinnamaldehyde-like

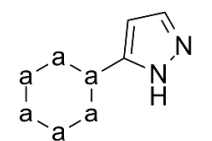$$
\text { Alert COX } 3
$$

5-Phenyl-1H-pyrazole-like 


\section{Dihydrofolate Reductase} 10

\section{GAR Transformylase}

$\begin{array}{lrr}\text { Alert DHFR } 1 \text { (SMILES) - Diaminopyrimidine } & \mathrm{S}, \mathrm{L}^{55}, \mathrm{X}^{56} & 145 / 237 \\ \text { Alert DHFR } 1 \text { (SMARTS) - Diaminopyrimidine-like } & \mathrm{S}, \mathrm{L}^{55}, \mathrm{X}^{56} & 158 / 237\end{array}$<smiles>Nc1ccnc(N)n1</smiles>

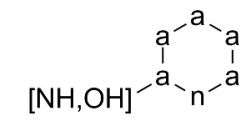

Alert DHFR 1 (SMILS) Alert DHFR 1 (SMARTS) Diaminopyrimidine Diaminopyrimidine-like
Alert HDAC 11 - Hydroxamic acids

Alert HDAC 12 a - Benzamide

Alert HDAC $12 b$ - Benzamide-like SMARTS

Alert HDAC $12 \mathrm{c}$ - Acetanilide

Alert HDAC $12 d$ - Acetanilide-like SMARTS

Alert HDAC $12 \mathrm{e}$ - Benzanilide

Alert HDAC $12 f$ - Benzanilide-like SMARTS

$\begin{array}{ll}S, L^{57,58} & 416 / 882 \\ S, L^{57,58} & 271 / 882 \\ S, L^{57,58} & 316 / 882 \\ S, L^{57,58} & 355 / 882 \\ S, L^{57,58} & 372 / 882 \\ S, L^{57,58} & 165 / 882 \\ S, L^{57,58} & 198 / 882\end{array}$

ACS Paragon Plus Environment

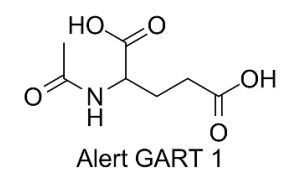

N-Acetyl-DL-glutamic acid 


\section{Monoamine Oxidase}

\section{Phosphodiesterases}

Alert MAO A 1 - 3-Phenyl-2-oxazolidone

Alert MAO A 2a - 4-Methylphenol

Alert MAO A 2b - 3-Methylphenol

Alert MAO A 2c - Methyl-3,4-diphenol

Alert MAO A 3a-Aminomethiazole

Alert MAO A 3b - 4-Phenyl-1,3-thiazole-2-amine

Alert MAO A 3c - CID 7958070

$\begin{array}{cc}\mathrm{L}^{59,60} & 12 / 382 \\ \mathrm{~S} & 99 / 382 \\ \mathrm{~S} & 80 / 382 \\ \mathrm{~S} & 10 / 382 \\ \mathrm{~S} & 58 / 382 \\ \mathrm{~S} & 57 / 382 \\ \mathrm{~S} & 54 / 382\end{array}$

$S, X^{61}$

$18 / 94$

Alert PDE 3A 2a - PDE Frag 3

Alert PDE 3A 2b - PDE Frag 3-like SMARTS

Alert PDE 3A 3 - PDE 3A Frag 4

Alert PDE 3A 4 - Veratrol-like
$S, X^{61}$

$11 / 94$

$S, X^{61}$

$15 / 94$

$\mathrm{S}$

$34 / 94$

$S, X^{61}$

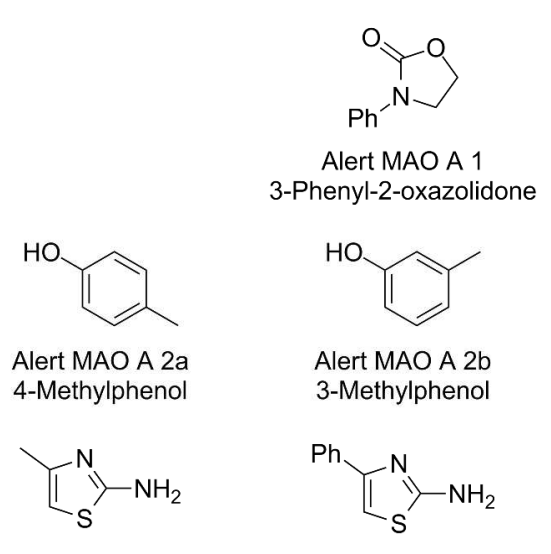

Alert MAO A 3a Aminomethiazole
Alert MAO A 3b

4-Phenyl-1,3-thiazole-2-amine

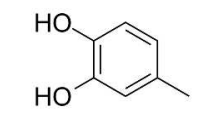

Alert MAO A 2c Methyl-3,4-diphenol

$\mathrm{Ph}$

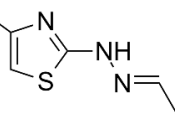

Alert MAO A 3c CID 7958070
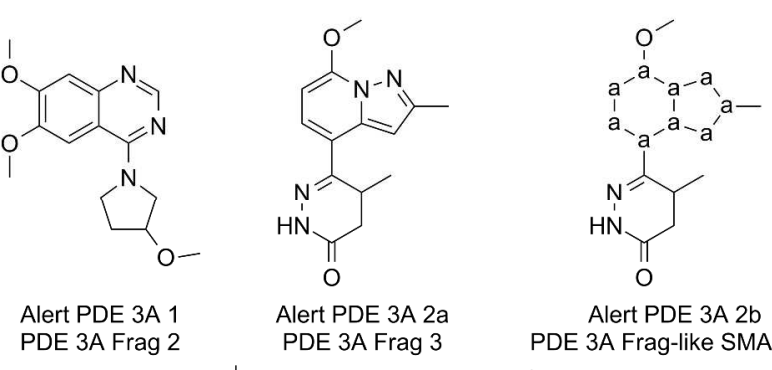

Alert PDE 3A 2b PDE 3A Frag 2 PDE 3A Frag-like SMARTS

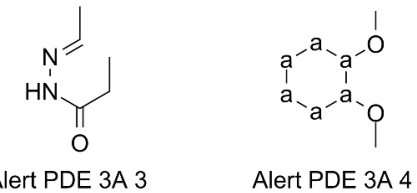




S 24/267

S $\quad 74 / 267$

14 Thymidylate Synthase

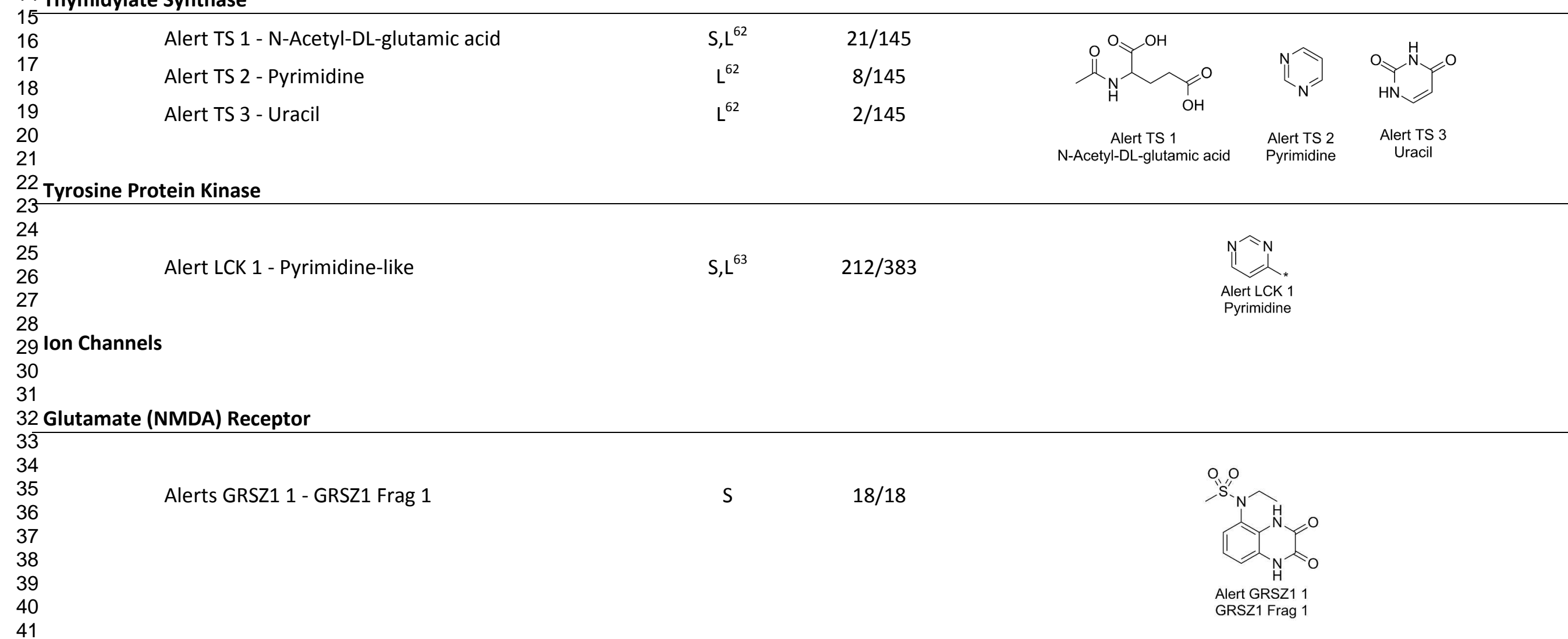


Origin

Training Set Hits

Alerts

\section{Potassium Voltage Gated Channel Subunit H Member 2}

Alert HERG 1a - Flex Aromatic Amine 1-5

$\begin{array}{ll}S, P^{64-67} & 167 / 215 \\ S, P^{64-67} & 147 / 215\end{array}$

$a^{-a}-a$
$a_{-}-a-a$
1

Alert HERG 1a

Flex Aromatic Amine 1-5

$$
\begin{aligned}
& a^{-a}-a \\
& 1 \\
& a_{-}-a-a(-*) \\
& 1
\end{aligned}
$$

Alert HERG $1 b$ Flex Aromatic Amine 2-5

\section{Serotonin 3A Receptor}

18
19
20
21
22
23
24
25
26
27
28
29
30
31
32
33
34
35
36
37
38
39
40
41
42
43
44
45
46

Alert S3AR 1 - S3AR Frag 1

Alert S3AR 2 - 1-[2-(Phenylsulfanyl)phenyl]piperazine

$47 / 229$

$S, L^{69}$

$27 / 229$

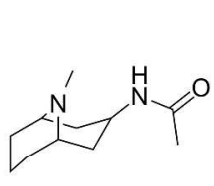

Alert S3AR 1 5 HT 3a Frag

1-[2-(Phenylsulfanyl)phenyl]piperazine

\section{Sodium Channel V Subunit alpha}

Alert SCV-A 1a - Pyrimidine-like aromatic

Alert SCV-A $1 b$ - Pyrimidine-like wildcard

Alert SCV-A 2 - 4-(4-Piperidineyloxy)pyrimidine

Alert SCV-A 3 - SCV Frag 1

Alert SCV-A 4 - N-(2-Phenylethyl)acetamide

$49 / 111$

\section{S}

$\mathrm{S}$

$49 / 111$

S

S

$30 / 111$

28/111

S

25/111

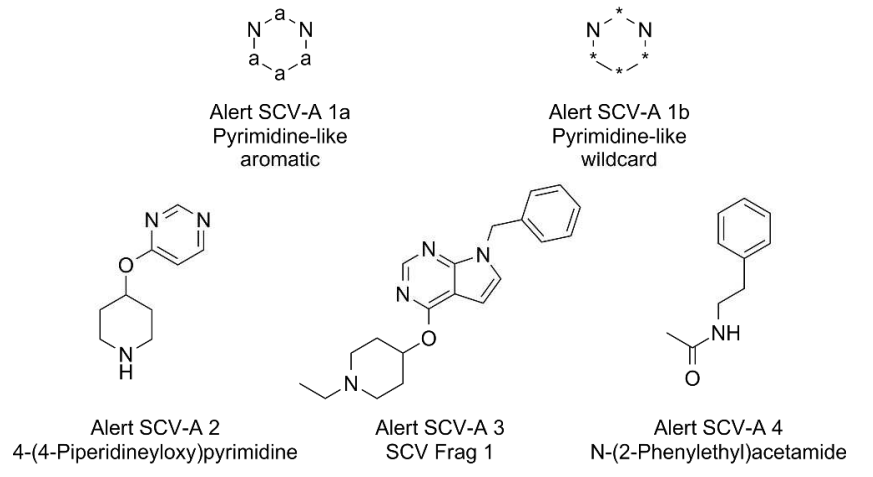




\section{Transporters}

11 Dopamine Transporter

19 Norepinephrine Transporter

$\begin{array}{lcc}\text { Alert DT } 1 \text { - 3-Phenyl-8-azabicyclo[3.2.1]octane } & \mathrm{S}, \mathrm{L}^{76,77} & 147 / 1159 \\ \text { Alert DT } 2 \text { - Diphenylmethane-like } & \mathrm{S}, \mathrm{L}^{78} & 268 / 1159\end{array}$

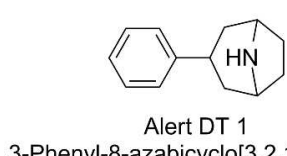

Alert DT 1
3-Phenyl-8-azabicyclo[3.2.1]octance

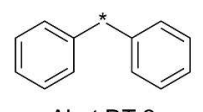

Alert DT 2

Diphenylmethane-like
Alert NT 1a - Cocaine-like 1

Alert NT 1b - Cocaine-like 2

Alert NT 1c - Cocaine-like 3

Alert NT 1d - Cocaine-like 4

Alert NT 2 - Amphetamines-like

$\begin{array}{lc}\text { S, } \text { L }^{79} & 60 / 1573 \\ \text { S, } \mathrm{L}^{79} & 61 / 1573 \\ \mathrm{~S}, \mathrm{~L}^{79} & 106 / 1573 \\ \mathrm{~S}, \mathrm{~L}^{79} & 117 / 1573 \\ \mathrm{~S}, \mathrm{~L}^{79} & 1164 / 1573\end{array}$

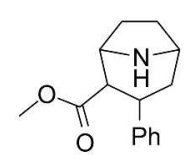

Alert NT 1a Cocaine-like 1

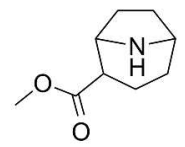

Alert NT 1b Cocaine-like 2

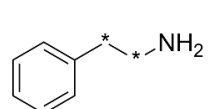

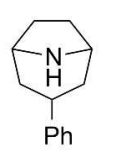
Alert NT 1c Alert NT 1d Cocaine-like 3 Cocaine-like 4

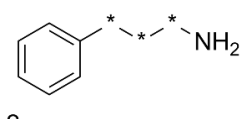

Alert NT 2

Amphetamines-like

\section{Serotonin Transporter}

Alert ST 1 - 3-Ethyl-indole

Alert ST 2 - DMEA

Alert ST 3 - Benzyloxybenzene

Alert ST 4 - Diphenylmethane

$\begin{array}{lc}S, L^{80} & 175 / 2166 \\ S, L^{80} & 1438 / 2166 \\ S, L^{80} & 172 / 2166 \\ S, L^{80} & 192 / 2166\end{array}$

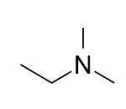

Alert ST 2 DMEA

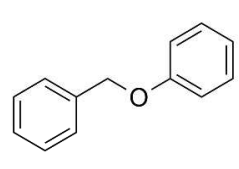

Alert ST 3 Benzyloxybenzene

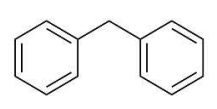

Alert ST 4 Diphenylmethane 
Table 2. Structural alerts developed for each receptor with the fraction of hits within each training set shown. Alerts are labelled based on their origin, S for fragments identified by maximal common substructure search using Pipeline Pilot, L for fragments found in typical ligands found in the literature, $\mathrm{P}$ for fragments based on an existing pharmacophore and $\mathrm{X}$ for fragments derived from an existing crystal structure. Alerts are shown pictorially as they have been coded in SMARTS or SMILES, with aromatic heavy atoms depicted as (a), aliphatic heavy atoms depicted as (A), and wildcard atoms (any heavy atom) depicted as (*). 


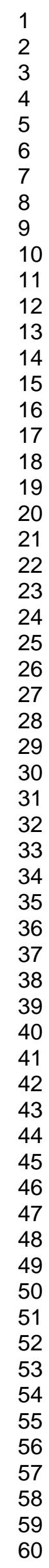

ACS Paragon Plus Environment 


\begin{tabular}{llllllllll} 
Receptor & MIE & TP & FN & TN & FP & SE & SP & Q & MCC \\
\hline
\end{tabular}

\section{G-Protein Coupled Receptors}

\section{Adenosine A2a Receptor}

Alert AA2aR 1 - 2-Aminopyrimidine

$\begin{array}{cccccccc}319 & 491 & 10591 & 229 & 39.4 & 97.9 & 93.8 & 0.448 \\ 251 & 559 & 10441 & 379 & 31.0 & 96.5 & 91.9 & 0.309 \\ 505 & 305 & 10343 & 477 & 62.3 & 95.6 & 93.3 & 0.530 \\ 65 & 745 & 10689 & 131 & 8.0 & 98.8 & 92.5 & 0.135 \\ 137 & 673 & 10771 & 49 & 16.9 & 99.5 & 93.8 & 0.334 \\ 155 & 655 & 10820 & 0 & 19.1 & 100.0 & 94.4 & 0.425\end{array}$

\section{Adrenergic Receptors}

Alpha-1a/-2a Alert A-ADR 1 - Phenylpiperazine-like

Alert A-ADR 2 - Tolazoline-like

$\begin{array}{cccccccc}69 & 234 & 10318 & 1009 & 22.8 & 91.1 & 89.3 & 0.076 \\ 6 & 297 & 11326 & 1 & 2.0 & 100.0 & 97.4 & 0.128 \\ & & & & & & & \\ 6 & 189 & 11136 & 299 & 3.1 & 97.4 & 95.8 & 0.004 \\ 54 & 141 & 10705 & 730 & 27.7 & 93.6 & 92.5 & 0.109 \\ & & & & & & & \\ 24 & 86 & 11513 & 7 & 21.8 & 99.9 & 99.2 & 0.408 \\ 22 & 88 & 11507 & 13 & 20.0 & 99.9 & 99.1 & 0.351 \\ 24 & 86 & 11505 & 15 & 21.8 & 99.9 & 99.1 & 0.363 \\ 6 & 104 & 11484 & 36 & 5.5 & 99.7 & 98.8 & 0.083 \\ 3 & 107 & 11515 & 5 & 2.7 & 100.0 & 99.0 & 0.099 \\ 10 & 100 & 11342 & 178 & 9.1 & 98.5 & 97.6 & 0.058 \\ 22 & 88 & 11515 & 5 & 20.0 & 100.0 & 99.2 & 0.401\end{array}$




\begin{tabular}{|c|c|c|c|c|c|c|c|c|c|}
\hline Receptor & MIE & TP & FN & TN & FP & SE & SP & $\mathbf{Q}$ & MCC \\
\hline \multirow[t]{4}{*}{ Beta } & Alert B-ADR 1 - 1-(Phenethylamino)propan-2-ol-like & 168 & 203 & 11154 & 105 & 45.3 & 99.1 & 97.4 & 0.515 \\
\hline & Alert B-ADR 2 - 2-(Ethylamino)-1-phenylethanol-like & 242 & 129 & 11207 & 52 & 65.2 & 99.5 & 98.4 & 0.725 \\
\hline & Alert B-ADR 3 - 1-(Ethylamino)-3-phenoxyl-2-propanol-like & 102 & 269 & 11178 & 81 & 27.5 & 99.3 & 97.0 & 0.378 \\
\hline & Alert B-ADR 1 OR 2 OR 3 & 350 & 21 & 11025 & 234 & 94.3 & 97.9 & 97.8 & 0.742 \\
\hline \multicolumn{10}{|c|}{ Cannabinoid Receptor } \\
\hline \multirow[t]{6}{*}{ CB1 } & Alert CCB1R 1 - 2-Phenylpyrazole-like & 170 & 880 & 10296 & 284 & 16.2 & 97.3 & 90.0 & 0.200 \\
\hline & Alert CCB1R 2 - 5-Phenyl-1H-pyrazole-like & 117 & 933 & 10445 & 135 & 11.1 & 98.7 & 90.8 & 0.194 \\
\hline & Alert CCB1R 3 - Pyrazole-3-carboxamide & 148 & 902 & 10533 & 47 & 14.1 & 99.6 & 91.8 & 0.305 \\
\hline & Alert CCB1R 1 OR 2 & 178 & 872 & 10210 & 370 & 17.0 & 96.5 & 89.3 & 0.182 \\
\hline & Alerts CCB1R 1 AND 2 & 109 & 941 & 10531 & 49 & 10.4 & 99.5 & 91.5 & 0.246 \\
\hline & Alerts CCB1R 1, 2 AND 3 & 86 & 964 & 10576 & 4 & 8.2 & 100.0 & 91.7 & 0.267 \\
\hline \multirow[t]{2}{*}{ CB2 } & Alert CCB2R 1 - CCB2R Frag 1 & 111 & 859 & 10612 & 48 & 11.4 & 99.5 & 92.2 & 0.262 \\
\hline & Alert CCB2R 2 - 1-(1-Ethyl-1H-pyrrol-3-yl)ethanone & 96 & 874 & 10621 & 39 & 9.9 & 99.6 & 92.1 & 0.246 \\
\hline $\mathrm{CB} 1 \&$ CB2 & Alert CR 1 - Indole & 207 & 1594 & 9043 & 786 & 11.5 & 92.0 & 79.5 & 0.045 \\
\hline \multicolumn{10}{|c|}{ Cholecystokinin A Receptor } \\
\hline & Alert CCKAR 1 - 2-Acetamido-N-methylacetamide & 35 & 43 & 11209 & 343 & 44.9 & 97.0 & 96.7 & 0.193 \\
\hline & Alert CCKAR 2 - N-[2-(methylamino)ethyl]acetamide & 76 & 2 & 10595 & 957 & 97.4 & 91.7 & 91.8 & 0.256 \\
\hline & Alert CCKAR 3 - CID 9957635 & 30 & 48 & 11552 & 0 & 38.5 & 100.0 & 99.6 & 0.619 \\
\hline
\end{tabular}


FN

TN

FP

SE

SP $\quad \mathbf{M} \quad$ MCC

\section{Dopamine Receptor}

\begin{tabular}{|c|c|c|c|c|c|c|c|c|c|}
\hline \multirow[t]{4}{*}{ D1 } & Alert DD1R 1 - Dihydrexine-like & 10 & 121 & 11447 & 52 & 7.6 & 99.5 & 98.5 & 0.104 \\
\hline & Alert DD1R 2 - Benzazepine-like & 9 & 122 & 11454 & 45 & 6.9 & 99.6 & 98.6 & 0.101 \\
\hline & Alert DD1R 3 - Benzazepine-like with aromatic & 9 & 122 & 11499 & 0 & 6.9 & 100.0 & 99.0 & 0.261 \\
\hline & Alert DD1R 4 - CID 15288 & 32 & 99 & 11472 & 27 & 24.4 & 99.8 & 98.9 & 0.359 \\
\hline \multirow[t]{3}{*}{ D2 } & Alert DD2R 1 - Piperazine & 417 & 341 & 9678 & 1194 & 55.0 & 89.0 & 86.8 & 0.315 \\
\hline & Alert DD2R 2 - 1,4 Dimethylpiperazine & 416 & 342 & 9928 & 944 & 54.9 & 91.3 & 88.9 & 0.355 \\
\hline & Alert DD2R 3 - Phenylpiperazine & 321 & 437 & 10285 & 587 & 42.3 & 94.6 & 91.2 & 0.340 \\
\hline \multicolumn{10}{|c|}{ Endothelin Receptor A } \\
\hline & Alert ER ET-A 1 - 5-Ethyl-1,3-benzodioxole & 3 & 25 & 11573 & 29 & 10.7 & 99.8 & 99.5 & 0.098 \\
\hline & Alert ER ET-A 2 - N-Methylbenzenesulfonamide-like & 18 & 10 & 11107 & 495 & 64.3 & 95.7 & 95.7 & 0.143 \\
\hline & Alert ER ET-A 3 - Tryptamine & 8 & 20 & 11340 & 262 & 28.6 & 97.7 & 97.6 & 0.086 \\
\hline & Alert ER ET-A 4 - ER ET-A Frag 1-like & 14 & 14 & 11602 & 0 & 50.0 & 100.0 & 99.9 & 0.707 \\
\hline & Alert ER ET-A 5 - N-Methyl-2-biphenylsulfonamide-like & 13 & 15 & 11585 & 17 & 46.4 & 99.9 & 99.7 & 0.447 \\
\hline & Alert ER ET-A 4 OR 5 & 14 & 14 & 11585 & 17 & 50.0 & 99.9 & 99.7 & 0.474 \\
\hline \multicolumn{10}{|c|}{ Histamine Receptors } \\
\hline \multirow[t]{2}{*}{ H1 } & Alert HH1R 1 - Doxepine-like & 24 & 134 & 11106 & 366 & 15.2 & 96.8 & 95.7 & 0.077 \\
\hline & Alert HH1R 2 - 4-Phenoxypiperidine & 21 & 137 & 11412 & 60 & 13.3 & 99.5 & 98.3 & 0.178 \\
\hline \multirow[t]{4}{*}{ H2 } & Alert HH2R 1 - Imidazole & 15 & 33 & 10635 & 947 & 31.3 & 91.8 & 91.6 & 0.054 \\
\hline & Alert HH2R 2 - Guanidine & 14 & 34 & 11408 & 174 & 29.2 & 98.5 & 98.2 & 0.141 \\
\hline & Alert HH2R 4 - Indole & 20 & 28 & 10609 & 973 & 41.7 & 91.6 & 91.4 & 0.076 \\
\hline & Alert $\mathrm{HH} 2 \mathrm{R}$ 1, 2 OR 4 & 38 & 10 & 9558 & 2024 & 79.2 & 82.5 & 82.5 & 0.104 \\
\hline
\end{tabular}


TN

FP

SE

SP Q MCC

\section{Muscarinic Acetylcholine Receptors}

\begin{tabular}{|c|c|c|c|c|c|c|c|c|c|}
\hline $\mathrm{M} 1$ and $\mathrm{M} 2$ & Alert MAR 1 - Formanilide & 102 & 270 & 9782 & 1476 & 27.4 & 86.9 & 85.0 & 0.074 \\
\hline $\mathrm{M} 2$ and $\mathrm{M} 3$ & Alert MAR 2 - N-Ethyl-N,N-dimethylpropanaminum & 129 & 282 & 11175 & 44 & 31.4 & 99.6 & 97.2 & 0.473 \\
\hline M3 & Alert MAR 3 - Tetramethylamonium & 118 & 177 & 11245 & 90 & 40.0 & 99.2 & 97.7 & 0.465 \\
\hline All & Alert MAR 4 - MAR Pharmacophore & 198 & 394 & 10541 & 497 & 33.4 & 95.5 & 92.3 & 0.268 \\
\hline \multicolumn{10}{|c|}{ Opioid Receptors } \\
\hline & Alert OR 1 - Morphine-like (4 or more) & 164 & 1221 & 10238 & 7 & 11.8 & 99.9 & 89.4 & 0.317 \\
\hline & Alert OR 1 - Morphine-like (3 or more) & 459 & 926 & 9867 & 378 & 33.1 & 96.3 & 88.8 & 0.369 \\
\hline & Alert OR 2 - 1-Methyl-4-phenylpiperidine & 668 & 717 & 9957 & 288 & 48.2 & 97.2 & 91.4 & 0.536 \\
\hline \multicolumn{10}{|c|}{ Serotonin Receptors } \\
\hline All & Alert SR 1 - 3-Ethyl Indole & 125 & 1041 & 9946 & 518 & 10.7 & 95.0 & 86.6 & 0.076 \\
\hline $1 A, 1 B, 2 A$ & Alert SR 1a1b2a 1 - 1-Methyl-4-Phenylpiperazine-like & 397 & 621 & 10011 & 601 & 39.0 & 94.3 & 89.5 & 0.336 \\
\hline $1 \mathrm{~A}$ & Alert SR 1a 1 - SR 1a Frag 2 & 33 & 471 & 11118 & 8 & 6.5 & 99.9 & 95.9 & 0.222 \\
\hline 1B & Alert SR 1b 1 - 2-Methyl-1,2-dihydroquinoline & 46 & 68 & 11323 & 193 & 40.4 & 98.3 & 97.8 & 0.269 \\
\hline \multirow[t]{2}{*}{ 2B } & Alert SR 2b 1 - CID 15206310 & 15 & 180 & 11425 & 10 & 7.7 & 99.9 & 98.4 & 0.211 \\
\hline & Alert SR 2b 2 - SR 2b Frag 2 & 8 & 187 & 11435 & 0 & 4.1 & 100.0 & 98.4 & 0.201 \\
\hline
\end{tabular}




\begin{tabular}{|c|c|c|c|c|c|c|c|c|c|}
\hline Receptor & MIE & TP & FN & TN & FP & SE & SP & $\mathbf{Q}$ & MCC \\
\hline \multicolumn{10}{|c|}{ Vasopressin V1a } \\
\hline & Alert VV1a 1 - VV1a Frag 1 & 70 & 110 & 10811 & 639 & 38.9 & 94.4 & 93.6 & 0.172 \\
\hline & Alert VV1a 2 - n-benzyl-n-ethylmethylamine & 90 & 90 & 9928 & 1522 & 50.0 & 86.7 & 86.1 & 0.131 \\
\hline & Alert VV1a 3 - VV1a Frag 3 & 66 & 114 & 11144 & 306 & 36.7 & 97.3 & 96.4 & 0.238 \\
\hline & Alert VV1a 4 - VV1a Frag 4 & 41 & 139 & 11372 & 78 & 22.8 & 99.3 & 98.1 & 0.271 \\
\hline
\end{tabular}

Enzymes

\section{Acetylcholinesterase}

$\begin{array}{lcccccccc}\text { Alert AC 1a - Tacrine } & 74 & 292 & 11261 & 3 & 20.2 & 100.0 & 97.5 & 0.435 \\ \text { Alert AC 1b - 4-Quinolinamine } & 77 & 289 & 11233 & 31 & 21.0 & 99.7 & 97.2 & 0.378 \\ \text { Alert AC 1c - AC Frag 1 } & 97 & 269 & 11261 & 3 & 26.5 & 100.0 & 97.7 & 0.501 \\ \text { Alert AC 1d - Dimethyl benzylamine } & 127 & 239 & 9596 & 1668 & 34.7 & 85.2 & 83.6 & 0.096 \\ \text { Alert AC 1e - Dimethyl benzylamine-like SMARTS } & 142 & 224 & 9710 & 1554 & 38.8 & 86.2 & 84.7 & 0.124\end{array}$

\section{Cyclooxygenases}

\begin{tabular}{|c|c|c|c|c|c|c|c|c|}
\hline Alert COX 1 - Sulfonated aromatic rings & 187 & 168 & 10567 & 708 & 52.7 & 93.7 & 92.5 & 0.299 \\
\hline Alert COX 2 - Cinnamaldehyde-like & 58 & 297 & 10912 & 363 & 16.3 & 96.8 & 94.3 & 0.121 \\
\hline Alert COX 3 - 5-Phenyl-1H-pyrazole-like & 34 & 321 & 11057 & 218 & 9.6 & 98.1 & 95.4 & 0.090 \\
\hline Alerts COX 1 OR 2 & 226 & 129 & 10218 & 1057 & 63.7 & 90.6 & 89.8 & 0.298 \\
\hline
\end{tabular}

\section{Dihydrofolate Reductase}

\begin{tabular}{|c|c|c|c|c|c|c|c|c|}
\hline Alert DHFR 1 (SMILES) - Diaminopyrimidine & 63 & 37 & 11397 & 133 & 63.0 & 98.8 & 98.5 & 0.444 \\
\hline Alert DHFR 1 (SMARTS) - Diaminopyrimidine-like & 65 & 35 & 10535 & 995 & 65.0 & 91.4 & 91.1 & 0.181 \\
\hline
\end{tabular}




\begin{tabular}{|c|c|c|c|c|c|c|c|c|c|}
\hline Receptor & MIE & TP & FN & TN & FP & SE & SP & $\mathbf{Q}$ & MCC \\
\hline \multicolumn{10}{|c|}{ GAR Transformylase } \\
\hline & Alert GART 1 - N-Acetyl-DL-glutamic acid & 10 & 3 & 11592 & 25 & 76.9 & 99.8 & 99.8 & 0.468 \\
\hline \multicolumn{10}{|c|}{ Histone Deacetylase 1} \\
\hline & Alert HDAC 11 - Hydroxamic acids & 147 & 173 & 11296 & 14 & 45.9 & 99.9 & 98.4 & 0.641 \\
\hline & Alert HDAC $12 \mathrm{a}$ - Benzamide & 83 & 237 & 10066 & 1244 & 25.9 & 89.0 & 87.3 & 0.077 \\
\hline & Alert HDAC $12 b$ - Benzamide-like SMARTS & 100 & 220 & 9846 & 1464 & 31.3 & 87.1 & 85.5 & 0.088 \\
\hline & Alert HDAC $12 \mathrm{c}$ - Acetanilide & 127 & 193 & 10380 & 930 & 39.7 & 91.8 & 90.3 & 0.179 \\
\hline & Alert HDAC $12 d$ - Acetanilide-like SMARTS & 135 & 185 & 9654 & 1656 & 42.2 & 85.4 & 84.2 & 0.125 \\
\hline & Alert HDAC $12 \mathrm{e}$ - Benanilide & 61 & 259 & 11173 & 137 & 19.1 & 98.8 & 96.6 & 0.226 \\
\hline & Alert HDAC $12 \mathrm{f}$ - Benanilide-like SMARTS & 73 & 247 & 11135 & 175 & 22.8 & 98.5 & 96.4 & 0.241 \\
\hline \multicolumn{10}{|c|}{ Monoamine Oxidase } \\
\hline & Alert MAO A 1 - 3-Phenyl-2-oxazolidone & 6 & 145 & 11477 & 2 & 4.0 & 100.0 & 98.7 & 0.171 \\
\hline & Alert MAO A 2a - 4-Methylphenol & 37 & 114 & 9431 & 2048 & 24.5 & 82.2 & 81.4 & 0.020 \\
\hline & Alert MAO A 2b - 3-Methylphenol & 35 & 116 & 9698 & 1781 & 23.2 & 84.5 & 83.7 & 0.024 \\
\hline & Alert MAO A 2c - Methyl-3,4-diphenol & 3 & 148 & 10901 & 578 & 2.0 & 95.0 & 93.8 & -0.016 \\
\hline & Alert MAO A 3a - Aminomethaziole & 26 & 125 & 11415 & 64 & 17.2 & 99.4 & 98.4 & 0.215 \\
\hline & Alert MAO A 3b - 4-Phenyl-1,3-thiazole-2-amine & 24 & 127 & 11452 & 27 & 15.9 & 99.8 & 98.7 & 0.268 \\
\hline & Alert MAO A 3c - CID 7958070 & 24 & 127 & 11479 & 0 & 15.9 & 100.0 & 98.9 & 0.396 \\
\hline \multicolumn{10}{|c|}{ Phosphodiesterases } \\
\hline \multirow[t]{5}{*}{ 3A } & Alert PDE 3A 1 - PDE 3A Frag 2 & 9 & 29 & 11592 & 0 & 23.7 & 100.0 & 99.8 & 0.486 \\
\hline & Alert PDE 3A 2a - PDE Frag 3 & 6 & 32 & 11592 & 0 & 15.8 & 100.0 & 99.7 & 0.397 \\
\hline & Alert PDE 3A 2b - PDE Frag 3-like SMARTS & 7 & 31 & 11592 & 0 & 18.4 & 100.0 & 99.7 & 0.429 \\
\hline & Alert PDE 3 A 3 - PDE 3A Frag 4 & 14 & 24 & 11574 & 18 & 36.8 & 99.8 & 99.6 & 0.400 \\
\hline & Alert PDE 3A 4 - Veratrol-like & 13 & 25 & 11139 & 453 & 34.2 & 96.1 & 95.9 & 0.088 \\
\hline
\end{tabular}




\begin{tabular}{|c|c|c|c|c|c|c|c|c|c|}
\hline Receptor & MIE & TP & FN & TN & $\mathbf{F P}$ & SE & SP & $\mathbf{Q}$ & MCC \\
\hline \multirow[t]{3}{*}{ 4D } & Alert PDE 4D 1 - Homoveratrol-like & 47 & 71 & 11311 & 201 & 39.8 & 98.3 & 97.7 & 0.264 \\
\hline & Alert PDE 4D 2 - 8-Isopropyl-1H-purine Frag & 19 & 99 & 11512 & 0 & 16.1 & 100.0 & 99.1 & 0.400 \\
\hline & Alert PDE 4D 3 - PDE 4D Frag 3 & 50 & 68 & 10932 & 580 & 42.4 & 95.0 & 94.4 & 0.165 \\
\hline \multicolumn{10}{|c|}{ Thymidylate Synthase } \\
\hline & Alert TS 1 - N-Acetyl-DL-glutamic acid & 13 & 41 & 11554 & 22 & 24.1 & 99.8 & 99.5 & 0.296 \\
\hline & Alert TS 2 - Pyrimidine & 2 & 52 & 11423 & 153 & 3.7 & 98.7 & 98.2 & 0.014 \\
\hline & Alert TS 1 AND 2 & 1 & 53 & 11576 & 0 & 1.9 & 100.0 & 99.5 & 0.136 \\
\hline & Alert TS 3 - Uracil & 3 & 51 & 11537 & 39 & 5.6 & 99.7 & 99.2 & 0.059 \\
\hline
\end{tabular}

Tyrosine Protein Kinase

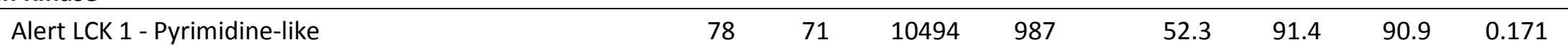

Ion Channels

Glutamate (NMDA) Receptor

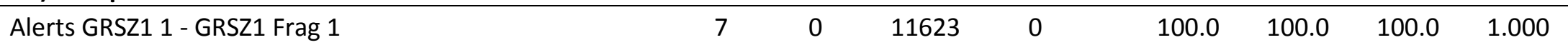

Potassium Voltage Gated Channel Subunit H Member 2

\begin{tabular}{|c|c|c|c|c|c|c|c|c|}
\hline Alert HERG 1a - Flex Aromatic Amine 1-5 & 60 & 20 & 5493 & 6057 & 75.0 & 47.6 & 47.7 & 0.037 \\
\hline Alert HERG $1 \mathrm{~b}$ - Flex Aromatic Amine 2-5 & 53 & 27 & 6046 & 5504 & 66.3 & 52.3 & 52.4 & 0.031 \\
\hline
\end{tabular}

\section{Serotonin 3A Receptor}

\begin{tabular}{|c|c|c|c|c|c|c|c|c|}
\hline Alert S3AR 1 - S3AR Frag 1 & 12 & 74 & 11544 & 0 & 14.0 & 100.0 & 99.4 & 0.372 \\
\hline Alert S3AR 2 - 1-[2-(Phenylsulfanyl)phenyl]piperazine & 7 & 79 & 11533 & 11 & 8.1 & 99.9 & 99.2 & 0.175 \\
\hline Alert S3AR 1 or 2 & 19 & 67 & 11533 & 11 & 22.1 & 99.9 & 99.3 & 0.372 \\
\hline
\end{tabular}




\begin{tabular}{|c|c|c|c|c|c|c|c|c|c|}
\hline Receptor & MIE & TP & FN & TN & FP & SE & SP & $\mathbf{Q}$ & MCC \\
\hline \multicolumn{10}{|c|}{ Sodium Channel V Subunit alpha } \\
\hline & Alert SCA-A 1a - Pyrimidine-like aromatic & 24 & 18 & 10466 & 1122 & 57.1 & 90.3 & 90.2 & 0.096 \\
\hline & Alert SCA-A 1b - Pyrimidine-like wildcard & 24 & 18 & 10466 & 1122 & 57.1 & 90.3 & 90.2 & 0.096 \\
\hline & Alert SCA-A 2 - 4-(4-Piperidineyloxy)pyrimidine & 9 & 33 & 11588 & 0 & 21.4 & 100.0 & 99.7 & 0.462 \\
\hline & Alert SCA-A 3 - SCV Frag 1 & 8 & 34 & 11588 & 0 & 19.0 & 100.0 & 99.7 & 0.436 \\
\hline & Alert SCA-A 4 - N-(2-Phenylethyl)acetamide & 11 & 31 & 11133 & 455 & 26.2 & 96.1 & 95.8 & 0.068 \\
\hline \multicolumn{10}{|c|}{ Voltage Gated K Channel Subunit Kv7.1 } \\
\hline & Alert VGKC Kv7.1 1 - VGKV Kv7.1 Frag 1 & 7 & 0 & 11618 & 5 & 100.0 & 100.0 & 100.0 & 0.764 \\
\hline \multicolumn{10}{|c|}{ Nuclear Receptors } \\
\hline \multicolumn{10}{|c|}{ Androgen Receptor } \\
\hline & Alert AR 1a - Benzonitrile & 132 & 205 & 11075 & 218 & 39.2 & 98.1 & 96.4 & 0.366 \\
\hline & Alert AR $1 b$ - Nitrobenzene & 39 & 298 & 11191 & 102 & 11.6 & 99.1 & 96.6 & 0.164 \\
\hline & Alert AR 1c - Quinolone & 59 & 278 & 11247 & 46 & 17.5 & 99.6 & 97.2 & 0.303 \\
\hline & Alert AR 1a, 1b OR 1c & 230 & 107 & 10927 & 366 & 68.2 & 96.8 & 95.9 & 0.495 \\
\hline \multicolumn{10}{|c|}{ Glucocorticoid Receptor } \\
\hline & Alert GR 1a - GR Frag 1 & 74 & 378 & 11159 & 19 & 16.4 & 99.8 & 96.6 & 0.352 \\
\hline & Alert GR 1b - tert-Butylcyclohexane & 55 & 397 & 11145 & 33 & 12.2 & 99.7 & 96.3 & 0.265 \\
\hline & Alert GR 1c - GR Frag 4 & 68 & 384 & 11168 & 10 & 15.0 & 99.9 & 96.6 & 0.354 \\
\hline & Alert GR 1d - GR Frag 5 & 68 & 384 & 11023 & 155 & 15.0 & 98.6 & 95.4 & 0.192 \\
\hline & Alerts GR 1a OR 1c OR 1d & 76 & 376 & 11005 & 173 & 16.8 & 98.5 & 95.3 & 0.204 \\
\hline
\end{tabular}




\begin{tabular}{llllllllll} 
Receptor & MIE & TP & FN & TN & FP & SE & SP & Q & MCC \\
\hline
\end{tabular}

\section{Transporters}

\section{Dopamine Transporter}

\begin{tabular}{|c|c|c|c|c|c|c|c|c|}
\hline Alert DT 1 - 3-Phenyl-8-azabicyclo[3.2.1]octane & 63 & 372 & 11136 & 59 & 14.5 & 99.5 & 96.3 & 0.260 \\
\hline Alert DT 2 - Diphenylmethane-like & 101 & 334 & 9902 & 1293 & 23.2 & 88.5 & 86.0 & 0.068 \\
\hline
\end{tabular}

\section{Norepinephrine Transporter}

Alert NT 1a - Cocaine-like 1

Alert NT 1b - Cocaine-like 2

Alert NT 1c - Cocaine-like 3

Alert NT 1d - Cocaine-like 4

Alert NT 2 - Amphetamines-like

$9902 \quad 1293$

Serotonin Transporter

$\begin{array}{lcccccccc}\text { Alert ST } 1 \text { - 3-Ethyl-indole } & 78 & 749 & 10238 & 565 & 9.4 & 94.8 & 88.7 & 0.047 \\ \text { Alert ST } 2 \text { - DMEA } & 68 & 759 & 4256 & 6547 & 8.2 & 39.4 & 37.2 & -0.272 \\ \text { Alert ST 3 - Benzyloxybenzene } & 81 & 746 & 10635 & 168 & 9.8 & 98.4 & 92.1 & 0.146 \\ \text { Alert ST 4 - Diphenylmethane } & 227 & 600 & 10258 & 545 & 27.4 & 95.0 & 90.2 & 0.231\end{array}$

Table 3. Results for test sets of each receptor with the remaining test sets acting as negatives. $\mathrm{TP}=$ True Positive, $\mathrm{FN}=\mathrm{False}$ Negative, $\mathrm{TN}=$ True Negative, $\mathrm{FP}=$ False Positive, $\mathrm{SE}=$ Sensitivity, $\mathrm{SP}=$ Specificity, $\mathrm{Q}=$ Overall Quality, $\mathrm{MCC}=$ Matthews Correlation Coefficient. 
GPCRs

Adenosine A2a Receptor

Alpha-1a Adrenergic Receptor

Alpha-2a Adrenergic Receptor

Beta-1 Adrenergic Receptor

Beta-2 Adrenergic Receptor

Cannabinoid CB1 Receptor

Cannabinoid CB2 Receptor

Cholecystokinin Receptor A

Dopamine D1 Receptor

Dopamine D2 Receptor

Endothelin Receptor A

Histamine H1 Receptor

Histamine H2 Receptor

Muscarinic Acetylcholine Receptor M1

Muscarinic Acetylcholine Receptor M2

Muscarinic Acetylcholine Receptor M3

Delta Opioid Receptor

Kappa Opioid Receptor

Mu Opioid Receptor

Serotonin 1A Receptor

Serotonin 1B Receptor

Serotonin 2A Receptor

Serotonin 2B Receptor

Vasopressin V1A Receptor
Alert 1, 23 OR 4

Alert 1, 2 OR 3

Alert 1, 2, 3, 4, 5 OR 6

Alert 1, 2 OR 3 (beta alerts)

Alert 1, 2 OR 3 (beta alerts)

Alert 1, 2 OR 3

Alert 1 OR 2

Alert 1, 2 OR 3

Alert 1, 2, 3 OR 4

Alert 1, 2 OR 3

Alert 1, 2, 3, 4 OR 5

Alert 1 OR 2

Alert 1, 2 OR 4

Alert 1 OR 4

Alert 1, 2 OR 4

Alert 2, 3 OR 4

Alert 1 ( 3 or more) OR 2

Alert 1 (3 or more) OR 2

Alert 1 (3 or more) OR 2

Alert SR1, SR1a1b2a1 OR

SR1a1

Alert SR1, SR1a1b2a1 OR

SR1b1

Alert SR1 OR SR1a1b2a1

Alert SR1, SR2b1 OR SR2b2

Alert 1, 2, 3 OR 4
$505 \quad 305$

62.35

$57 \quad 138$

29.23

$43 \quad 67$

39.09

$182 \quad 7$

96.30

$215 \quad 15$

93.48

$179 \quad 871$

17.05

$207 \quad 763$

21.34

$\begin{array}{ll}76 & 2\end{array}$

97.44

$45 \quad 86$

34.35

$417 \quad 341$

55.01

$25 \quad 3$

89.29

$45 \quad 113$

28.48

$38 \quad 10$

79.17

$109 \quad 139$

43.95

7490

45.12

$128 \quad 167$

43.39

$\begin{array}{lll}268 & 241 & 52.65\end{array}$

$\begin{array}{lll}286 & 271 & 51.35\end{array}$

$353 \quad 306$

53.57

$313 \quad 191$

62.10

$98 \quad 16$

$140 \quad 310$

85.96

$37 \quad 158$

31.11

18.97

$133 \quad 47$

73.89 


\section{Enzymes}

Acetylcholinesterase

Cyclooxygenase 1

Cyclooxygenase 2

Dihydrofolate Reductase

GAR Transformylase

Histone Deacetylase 1

Monoamine Oxidase A

Phosphodiesterase 3A

Phosphodiesterase 4D

Thymidylate Synthase

Tyrosine-Protein Kinase

Ion Channels

Glutamate (NMDA) Receptor

Potassium Voltage Gated Channel KQT 1 Alert 1a

Alert 1 OR 2

Alert 1b, 2, 3 OR 4

Sodium Channel V Subunit Alpha

Voltage Gated K Channel Subunit Kv7.1 Alert 1

Serotonin 3A Receptor
Alert 1a, 1b, 1c, 1d, OR 1e

Alert 1, 2 OR 3

Alert 1, 2 OR 3

Alert 1 (SMARTS)

Alert 1

Alert 1, 2b, 2d OR 2f

Alert 1, 2a, 2b, 2c, 3a, 3b OR 3c

Alert 1, 2b, 3 OR 4

Alert 1, 2 OR 3

Alert 1, 2 OR 3

Alert 1

Alert 1

$27 \quad 11$

$78 \quad 40$

$17 \quad 37$

$78 \quad 71$

52.35

66.67

42.86

70.86

65.00

76.92

76.25

50.99

71.05

66.10

31.48
$19 \quad 67$

22.09

28

14

66.67

100.00 


\begin{tabular}{llccc} 
Target & & TP & FN & SE \\
\hline Nuclear Receptors & & & & \\
\hline Androgen Receptor & Alert 1a, 1b OR 1c & & & \\
Glucocorticoid Receptor & Alert 1a, 1b, 1c OR 1d & 230 & 107 & 68.25 \\
& & 76 & 376 & 16.81 \\
Transporters & & & & \\
\hline & & & & \\
Dopamine Transporter & Alert 1 OR 2 & 164 & 271 & 37.70 \\
Norepinephrine Transporter & Alert 1a, 1b, 1c, 1d OR 2 & 490 & 148 & 76.80 \\
Serotonin Transporter & Alert 1, 2, 3 OR 4 & 637 & 190 & 77.03
\end{tabular}

Table 4. Results for models of combined structural alerts for each receptor. TP=True Positive, FN=False Negative, $\mathrm{SE}=$ Sensitivity. 